\title{
Economic Impact of Recreation on the Upper Mississippi River System
}

\author{
by Bruce D. Carlson, \\ U.S. Army Engineer District, St. Paul \\ Dennis B. Propst, Daniel J. Stynes, \\ Michigan State University \\ R. Scott Jackson, \\ WES
}


The contents of this report are not to be used for advertising, publication, or promotional purposes. Citation of trade names does not constitute an official endorsement or approval of the use of such commercial products. 
by Bruce D. Carlson

U.S. Army Engineer District, St. Paul

St. Paul, MN 55101-1638

Dennis B. Propst, Daniel J. Stynes

Michigan State University

131 Natural Resources Building

East Lansing, Ml 48824-1222

R. Scott Jackson

U.S. Army Corps of Engineers

Waterways Experiment Station

3909 Halls Ferry Road

Vicksburg, MS 39180-6199

\section{Final report}

Approved for public release; distribution is unlimited

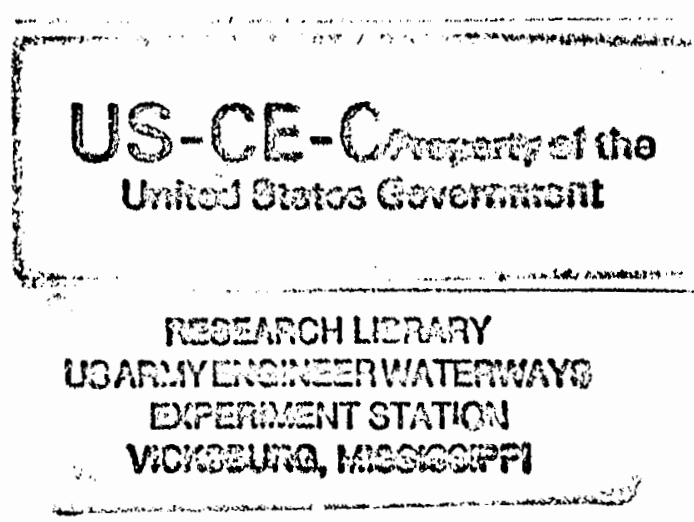




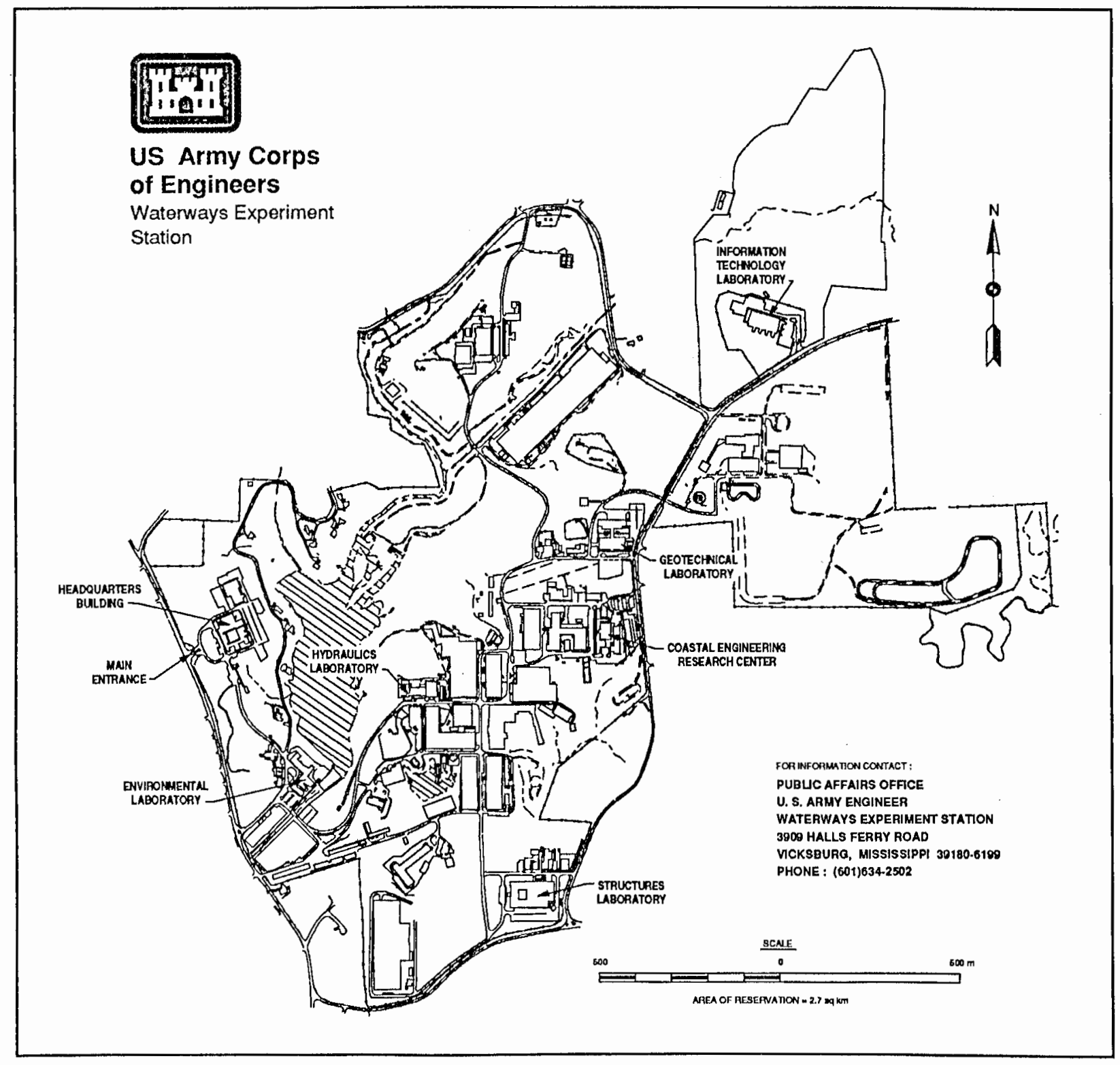

Waterways Experiment Station Cataloging-in-Publication Data

Economic impact of recreation on the upper Mississippi River System / by Bruce D. Carison ... [et al.] ; prepared for U.S. Army Corps of Engineers. 62 p. : ill. ; $28 \mathrm{~cm}$. - (Technical report ; EL-95-16) Includes bibliographical references.

1. Outdoor recreation - Mississippi River - Economic aspects. 2. Recreation areas - Mississippi River - Economic aspects. 3. Mississippi River - Recreational use. I. Carlson, Bruce D. II. United States. Army. Corps of Engineers. III. U.S. Army Engineer Waterways Experiment Station. IV. Environmental Laboratory (U.S. Army Engineer Waterways Experiment Station) V. Series: Technical report (U.S. Army Engineer Waterways Experiment Station) ; EL-95-16.

TA7 W34 no.EL-95-16 


\section{Contents}

Preface ............. vi

Summary ............. vii

1 -Introduction $\ldots \ldots \ldots \ldots$

Background ............. 1

Study Area ............ 2

2-Overview of Recreational Use

Study and Highlights of Results . . . 4

Study Plan Summary . . . . . . . 4

Summary of Trip Results ...... . 5

Summary of Activity Results . . . . 7

3-Survey of Developed Recreational Areas and Sightseeing Areas ..... 8

Methods ............... 8

Data Collection and Response . . . 8

Results ............. 9

Trip and activity estimatesUMRS total .......... 9

Trip and activity estimatesindividual regions ...... 10

Activity estimates-sightseeing areas/visitor centers . . . . . .

4-Survey of Permitted Dock Owners . 18

Methods .............. 18

Data Collection and Response .... 18

Results .............. 18

5-Survey of Marina Slip Renters/

Owners ............. 22

Methods ............. 22

Data Collection and Response . . . 22
Results ...........

6-Expenditure Survey and Economic Impact Results . . . . . . . . 27

Trip Expenditures . . . . . . . . 27

Recreation expenditure sampling plan methods . . . . . . . .

Expenditure data collection in connection with on-site surveys ........... 28

Expenditure data collection in connection with telephone surveys .................. 29

Results . . . . . . . . . . . . 29

Spending on Durable Goods . . . . 33

Economic Impact Analysis and IMPLAN .......... 35

Economic Effects . . . . . . . . 35

Regional Analysis . . . . . . 36

Economic effects of spending in the UMRS corridor counties . 36

Economic effects of spending on the five-state and national economies .......... 39

7-Applicability of Results . . . . . 41

Applications ............ 41

Opinions of Respondents ....... 41

Availability of the UMRS

for recreation ......... 42

Management issues of concern to respondents . . . . . . . . 42

Reason for selecting site . . . . . 42

Desired improvements at developed sites . . . . . . . 42

Problems encountered ....... 43 


\section{Desired improvements} on the UMRS ......... 43

General Limitations of Summary

Results........... 43

Bibliography ............ 45

Appendix A: Study Area Maps ..... A 1

SF 298

\section{List of Figures}

Figure 1. Study focused on water related recreational activities ........

Figure 2. Natural resources of the UMRS-an important draw for visitors . ...... 1

Figure 3. UMRS study area ...... 3

Figure 4. Recreational use associated with sightseeing areas included in scope of study .

Figure 5. Some activities were not included in study, such as use of riverfront attractions ......

Figure 6. Boating-most popular recreational activity in the UMRS ........

Figure 7. Recreational use of UMRS by access type (people) . . .

Figure 8. Activities breakdown, all surveys (sum of annual totals) ......

Figure 9. Recreational use of developed sites by region (people) ..... . 10

Figure 10. UMRS total (Regions 1-4) .

Figure 11. Activities breakdown, Region $1 \ldots \ldots$

Figure 12. Activities breakdown, Region $2 \ldots \ldots \ldots$
Figure 13. Activities breakdown,

Region $3 \ldots . . . .$.

Figure 14. Activities breakdown,

Region $4 \ldots \ldots$.....

Figure 15. Activity estimatessightseeing areas/ visitor centers .......

Figure 16. Recreational use of permitted docks by season (people) . . . .

Figure 17. Permitted docks (annual total, 1990-91) . . .

Figure 18. Recreational use of marina slips by season (people) ..

Figure 19. Marina slips

(annual total, 1991) .....

Figure 20. Total expenditures on UMRS trips, by access type .......

Figure 21. Expenditure segment shares, UMRS developed sites ......

Figure 22. Average trip spending per party/trip by segment, UMRS developed sites . . .

Figure 23. Total trip spending (\$MM) by segment, UMRS developed sites .....

Figure 24. Average trip spending per party/trip by spending category, UMRS developed sites ......

Figure 25. Total trip spending (\$MM), by spending category, UMRS developed sites ...

Figure 26, Durable goods expenditures related to UMRS trips, by access type

Figure A1. St. Paul District . . . . . A2

13 Figure A2. Rock Island District . . . . A3 
Figure A3. St. Louis District . . . . A4

Figure A4. Illinois River and Waterway ........ A5

\section{List of Tables}

Table 1. Study Treatment of UMRS

Recreation Access Types . . 5

Table 2. Recreational Trip and

Activity Estimates, UMRS

Total (Regions 1-4) . . . 11

Table 3. Recreational Trip and

Activity Estimates,

Sightseeing Areas/

Visitor Centers . . . . . . 16

Table 4. Recreational Trip and

Activity Estimates,

Permitted Docks

(Annual: 1990-91) . . . .

20

Table 5. Marina User Sample Sizes

and Response Rates

(UMRS Study, 1990-91).
Table 6. Recreational Trip and

Activity Estimates, Marina

Slips (Annual: 1991) ...

25

Table 7. User Segments for Trip

Expenditure Profiles . . . 28

Table 8. Characteristics of UMRS

Regional Economics

(1985 Figures) . . . . . . .

Table 9. Economic Effects of

Recreational Spending,

UMRS Corridor:

Grand Total ....... 38

Table 10. Economic Effects

of Recreational Spending,

Five States (MN, WI, IA,

IL, MO): Grand Total . . . 40

Table 11. Economic Effects of

Recreational Spending,

United States:

Grand Total ....... 40 


\section{Preface}

The study of the economic impacts of recreation on the Upper Mississippi River System (UMRS) was conducted as a part of the UMRS Environmental Management Program (EMP). The EMP is a long-term program designed to protect and balance the use of the resources of the Upper Mississippi and guide future river management. The program consists of five elements:

a. Habitat Rehabilitation and Enhancement Projects.

b. Long-Term Resource Monitoring.

c. Recreation Projects.

d. Study of Economic Impacts of Recreation.

e. Navigation Monitoring.

The work reported herein was a cooperative effort among the U.S. Army Engineer District (USAED), St. Paul; the U.S. Army Engineer Waterways Experiment Station (WES); and Michigan State University (MSU). Economic impact analysis procedures used in this study were developed under the Natural Resources Research Program.

This work was conducted by Mr. Bruce D. Carlson, Engineering and Planning Division, USAED, St. Paul; Drs. Dennis B. Propst and
Daniel J. Stynes, Department of Park and Recreation Resources, Michigan State University; and Mr. R. Scott Jackson, Natural Resource Division (NRD), Environmental Laboratory (EL), WES. The work was supervised by a multiagency Technical Review Team. Ms. Tracy C. Trichell, Computer Sciences Corporation, WES, provided assistance in assembling the final report.

The work was conducted under the direct supervision of Mr. H. Roger Hamilton, Chief, Resource Analysis Branch, NRD, and under the general supervision of Dr. Robert M. Engler, Chief, NRD, and Dr. John W. Keeley, Director, EL.

At the time of publication of this report, Director of WES was Dr. Robert W. Whalin. Commander was COL Bruce K. Howard, EN.

This report should be cited as follows:

Carlson, B. D., Propst, D. B., Stynes, D. J., and Jackson, R. S. (1995). "Economic impact of recreation on the Upper Mississippi River System," Technical Report EL-95-16, U.S. Army Engineer Waterways Experiment Station, Vicksburg, MS.

The contents of this report are not to be used for advertising, publication, or promotional purposes. Citation of trade names does not constitute an official endorsement or approval of the use of such commercial products. 


\section{Summary}

\section{Economic Impacts of Recreation on the Upper Mississippi River System}

The value of the Upper Mississippi River System (UMRS) as a national resource is being more widely recognized. The system is vital in supporting ecological systems, commercial navigation, and a wide variety of recreational activities.

To learn more about the monetary value of recreational use of the UMRS, Congress authorized a study in 1986 (Public Law 99-88) to measure the economic importance of recreation in the UMRS.

The study estimated that over 12 million daily visits by recreationists took place during the study year. These visits resulted in direct and secondary expenditures of over $\$ 1.2$ billion that helped maintain over 18,000 jobs nationwide.

\section{About the Study}

This study was conducted as a part of the UMRS Environmental Management Program (EMP). The EMP is a long-term program designed to protect and balance the resources of the Upper Mississippi River and guide future river management. The program consists of five elements:
- Habitat Rehabilitation and Enhancement Projects

- Long-Term Resource Monitoring

- Recreation Projects

- Study of Economic Impacts of Recreation

- Navigation Monitoring

This is the first study of the UMRS to produce basin-wide estimates of the total number of recreation visitors, the activities they engaged in, the amount of money they spent on recreation, and the patterns evident in their spending.

\section{Study Administration}

U.S. Army Engineer District, St. Paul

Technical Review Team

- Minnesota

- lowa

- Wisconsin

- Illinois

- Missouri

- U.S. Fish and Wildlife Service

- U.S. Army Corps of Engineers

The study was directed by the U.S. Army Engineer District, St. Paul, in active cooperation with the U.S. Fish and Wildlife Service, the National Park Service, and the states of Illinois, Missouri, Wisconsin, Iowa, and 
Minnesota. Representatives from these agencies comprised a technical review team that was responsible for the overall direction of the study.

An initial plan of study was developed and a review of existing studies was conducted. The literature review demonstrated that comprehensive data on recreational activities and spending did not exist. A sampling plan was devised to collect data to fill these gaps, with the intent of maximizing the relevance and quality of the data within the constraints of the study budget.

Three separate but related surveys were conducted to collect this data. Results of these surveys have been combined with a regional economic model (IMPLAN, developed by the U.S. Forest Service) to determine the overall impact of recreation on the regional economy.

The study focused on use of recreational areas that were most closely associated with management issues on the UMRS.

\section{Three Separate Surveys}

- Developed recreational areas and sightseeing overlooks.

- Permitted boat docks.

- Marina slips.

Data collection for developed sites along the river (and overlooks) was completed in November 1990, and resulted in 1,316 completed interviews. The telephone surveys measuring the use of permitted boat docks and marina slips were both completed in 1991. The surveys used panels of 150 households who were contacted up to 10 times throughout the survey year.

\section{Summary of Results}

The study focused on use of recreational areas that were most closely associated with management issues on the UMRS.

\section{Study Objectives}

Measurement of the amount and type of recreation use in the Upper Mississippi River System Measurement of recreation related spending by study area visitors.

Estimation of the economic impacts associated with that spending.

These included over 600 developed recreational areas and sightseeing overlooks; 18,000 marina slips; and 2,800 permitted boat docks.

Recreational use and spending related to other types of river access are not represented in these results.

\section{Results: Recreational Use}

More than 2.3 million recreational party trips to the UMRS were made to developed areas, sightseeing/ visitor center areas, marinas, and permitted docks during the study period. These trips equate to over 12 million daily visits by recreationists.

Boating, fishing, and sightseeing were the most popular activities. Half of all visitors boated.

Over 60 percent of the people made their trips to developed areas, with the remaining trips being made to marinas (26 percent), sightseeing/visitor center areas ( 7 percent) and permitted docks (4 percent).

Residents of counties that border the UMRS accounted for the majority of the trips, ranging from two-thirds to three-fourths for all types of access. Single day trips were predominant (around 75 percent) when compared with trips that included overnight stays. Average party sizes were larger for trips to permitted docks and marinas. 
Recreational Use of UMRS by Access Type (people)

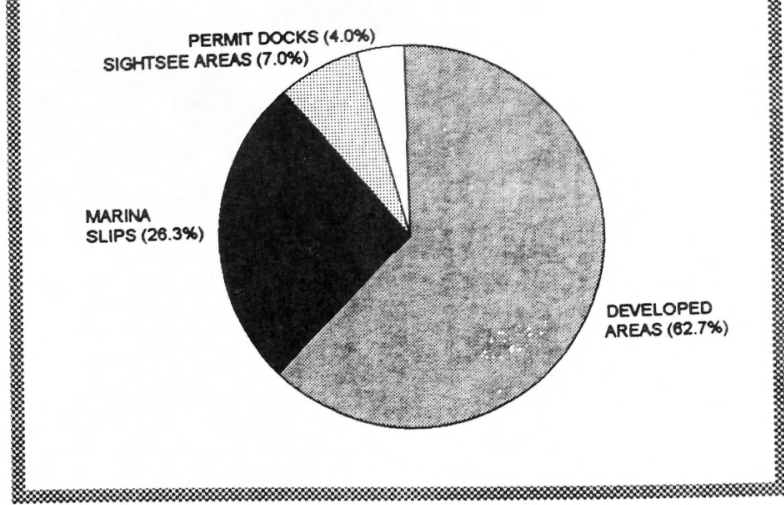

For developed areas, in which use was distinguished by four regions, the vast majority of the use ( 86 percent) took place in the St. Paul and Rock Island stretches of the UMRS. Since only system-wide estimates are available for the remaining types of access, regional distribution of use cannot be reported.

- There were over 12 million daily visits by recreationists during the study year.

- 75 percent of visits were by residents of counties that border the UMRS.

- 86 percent of visits to developed areas took place in the St. Paul and Rock Island stretches of the UMRS.

\section{Results: Recreational Spending (1990 Price Levels)}

Visitor spending was measured for items consumed on trips as well as for durable items (boats, trailers, etc.) that were used on trips. Visitors spent over $\$ 190$ million on items consumed on trips during the study year. Spending on durable items amounted to over $\$ 150$ million during the study year.

- The average spending per visitor per day for items consumed on trips was $\$ 15.84$.
- Most of this spending was for food, gas, lodging, and boating expenses.

Patterns in spending were evident. The most influential factors were distance traveled, length of trips (daily or overnight), and use or nonuse of boats. These patterns have been identified in "expenditure profiles" and can be used in future studies in the UMRS.

- Spending on durable items used on trips, such as boats and fishing gear, averaged $\$ 12.54$ per visitor per day.

- Most of this spending was on boating equipment, camping vehicles, and fishing gear.

Visitors to marinas spent more, on average, than visitors to other areas. The value of all boats in marinas was approximately $\$ 600 \mathrm{mil}$ lion.

\section{Results: Economic Impacts (1990 Price Levels)}

Economic impact analyses attempt to measure the effect of spending on local, regional, or national economies. Where spending takes place and how much spending is made locally by nonresident visitors are of particular interest. Determining the types of goods purchased and the sectors of the economy that produce these goods is key to the analysis.

Recreational activity on the UMRS during the study year resulted in direct and secondary expenditures of $\$ 1.2$ billion that helped maintain 18,500 jobs nationwide.

- Recreational activities in the 76 counties bordering the UMRS during the study year resulted in direct and secondary expenditures of $\$ 400$ million that helped maintain 7,200 jobs. 
- Service industries, retailers, manufacturers, and finance and insurance providers were affected most.

\section{Activities Breakdown All Surveys (sum of annual totals)}

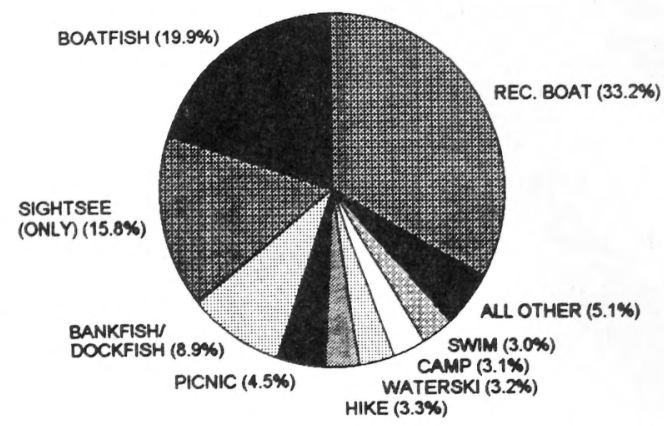

Types of Recreational Access Not Included:

- Dispersed use areas/undeveloped areas

- Urban river corridor parks (unlimited access)

- Private clubs (hunting, etc.)

- Riparian households without permitted docks

- Commercial boat tours/Gambling boats

- Boaters who pass through the entire UMRS

One-third of all spending in the 76 corridor counties was made by nonresidents, representing "new dollars" to the region. Over 75 percent of the overall effects of those "new dollars" occurred in counties along the UMRS in the St. Paul District. Since durable goods can be used at many sites for many purposes, only durable goods that were purchased in the 76 corridor counties were considered when estimating economic impacts. (Recreational vehicles were not included.)

\section{Comparability of Results}

A number of checks on the study results have led to the conclusion that the study results provide a good representation of recreational activity during the study year. The results compared favorably to several regional studies conducted during similar time periods by the Iowa, Minnesota, and Wisconsin Departments of Natural Resources. Internal measures were also considered. The overall use counts, for example, were estimated at less than 10-percent error at a 90-percent confidence level.

Individuals interested in comparing other study results with those of this study should be careful to avoid a number of common pitfalls. Variables that need to be considered when making comparisons of recreational use and expenditures include: types of access (only developed areas, marinas, and permitted docks are measured by this study); units of party measurement (individuals or parties); units of trip measurement (hours, days, visits, trips); and types of expenditures (consumed goods and services or durable goods). It is also important to distinguish economic impact analyses (which focus on actual expenditures) from benefit-cost analyses (which compare "economic value" or "willingness to pay" with costs to determine "consumer surplus" or "net benefit"). Planners interested in this type of exercise should request study reports to better understand how the study results were generated and reported.

\section{Study Applications}

The study products will enable managers and planners to conduct economic impact studies at the local level practically and confidently. Such studies have been impractical in the past because visitor spending patterns, 
and their relationship to local economies, were not known and were costly to determine.

Reports documenting the study methods and results and training sessions in study methods and the use of the regional economic model (IMPLAN) have been presented to UMRS planners. Training in the study methods and use of the IMPLAN regional economic model was held in 1992. Over 20 individuals received the training, representing a variety of state and Federal agencies, and universities. These stakeholders and policymakers will use the study products directly in decision-making regarding economic development, river use allocation, and resource protection.

Anticipated applications of study results include justification of new programs or facilities, such as marina expansion or new boat ramps; evaluation of alternative management options, taking into account the balance of river uses and environmental integrity; consideration of cost-sharing approaches; and comparison of economic development options.

The study will also provide a necessary link in assessing overall demand for the UMRS as a resource and in assessing its economic and environmental carrying capacity. The study results will make it more possible to achieve a comprehensive strategy for managing the UMRS. The study results can be used in combination with natural resource monitoring data and commercial navigation data to evaluate the economic output potential and environmental sustainability of the UMRS as a national resource. 



\section{Introduction}

\section{Background}

In 1986, Congress authorized a study to assess the economic importance of recreation in the Upper Mississippi River System (UMRS) (Public Law 99-88) (Figure 1). The study was conducted as a part of the UMRS Environmental Management Program (EMP). The EMP is a long-term program designed to protect and balance the resources of the Upper Mississippi and guide future river management (Figure 2). The program consists of five elements:

- Habitat Rehabilitation and Enhancement Projects

- Long-Term Resource Monitoring

- Recreation Projects

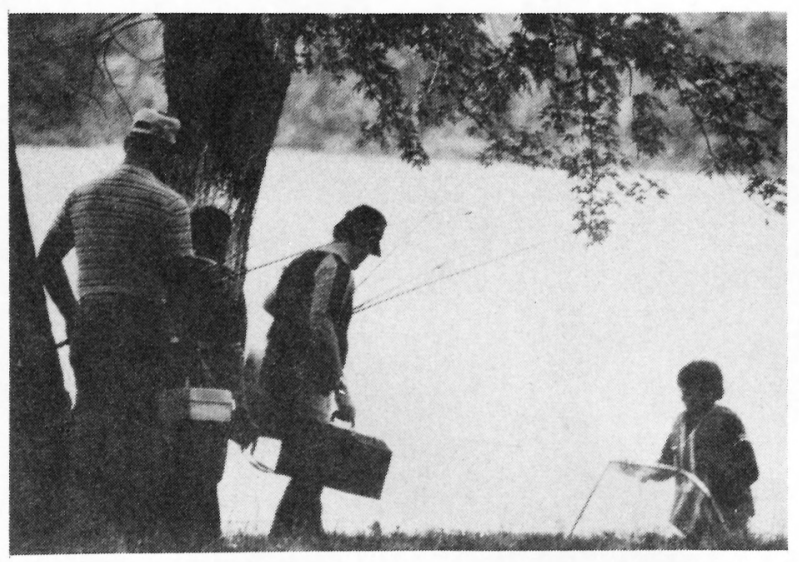

Figure 1. Study focused on water related recreational activities
- Study of Economic Impacts of Recreation

- Navigation Monitoring

The study of the economic impacts of recreation on the UMRS was administered by the U.S. Army Engineer District (USAED), St. Paul, and supervised by a multiagency Technical Review Team (TRT). It had two distinct but related components:

a. Measurement of the amount and type of recreational use in the UMRS through the use of on-site interviews at public access sites in the study area and telephone interviews of households that rent marina slips or have permitted boat docks.

$b$. Measurement of recreation-related spending by the respondents in component $a$. Durable recreational goods spending

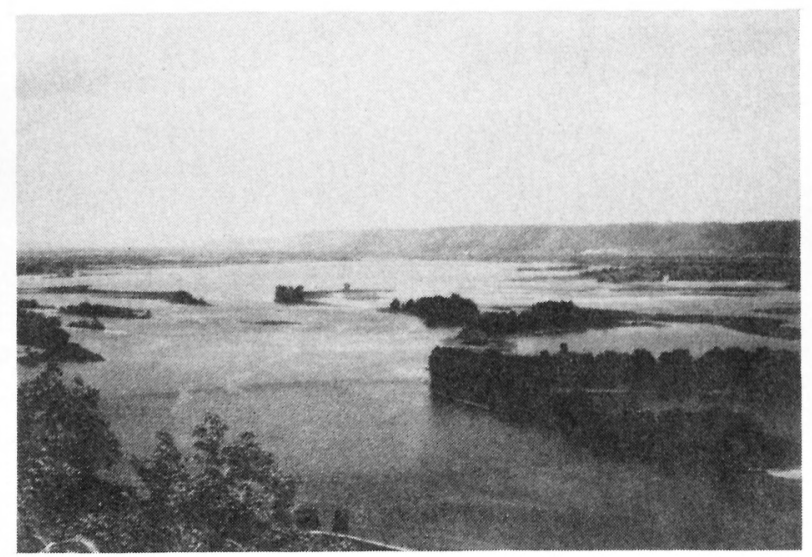

Figure 2. Natural resources of the UMRS-an important draw for visitors 
will be measured through the on-site interviews and initial phone calls, while variable trip spending will be measured with a self-administered mailback questionnaire.

The economic impacts of recreational activity on the economies of the UMRS region were measured using the results of the recreational use and expenditure components. Input-Output analysis was used to estimate the effects of spending on the regional economy. The automated econometric model IMPLAN (IMPact analysis for PLANning), developed by the U.S. Forest Service, was used for this purpose.

\section{Study Area}

Geographically, the study includes the commercially navigable portions of five rivers: the Mississippi (north of Cairo, IL), Illinois, St. Croix, Minnesota, and Kaskaskia (Figure 3). The UMRS is composed of nearly 1,300 miles of commercially navigable waters. Also included in the study area are the side channels, sloughs, and lakes associated with these rivers, as well as the land immediately adjacent to them. The study area is contained within the states of Minnesota, Wisconsin, Iowa, Illinois, and Missouri.

The 76 counties (plus the city of St. Louis) that border the UMRS study area have been used to define the "local" area in this study (Appendix A).

This definition of local is used when describing visitors as resident or nonresident and is also used when considering economic impacts. 


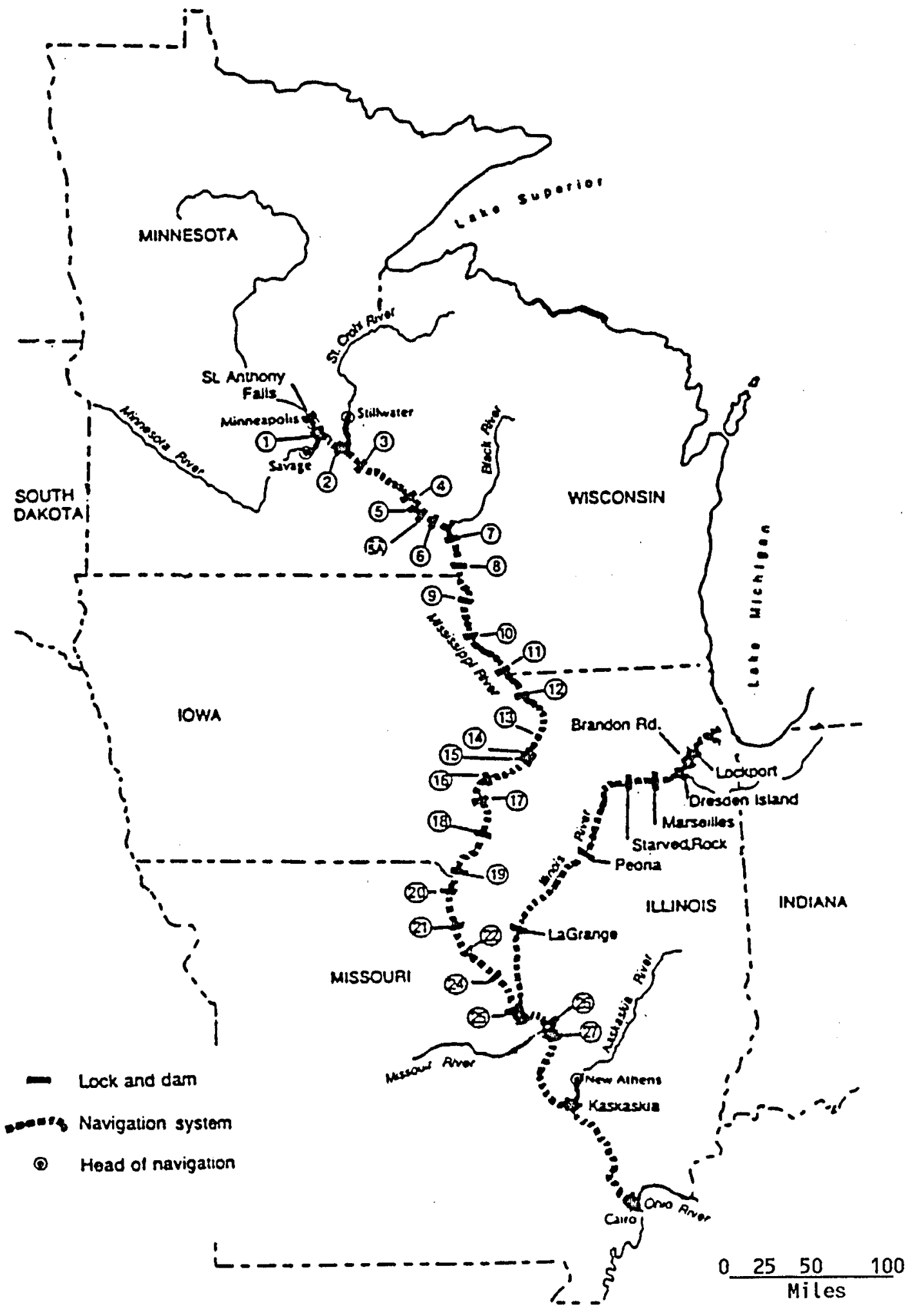

Figure 3. UMRS study area 


\section{Overview of Recreational Use Study and Highlights of Results}

\section{Study Plan Summary}

To meet the study objectives of measuring recreational use and associated expenditures on the UMRS, the TRT concluded that an independent survey effort was the only viable approach (Figures 4 and 5). Despite the large number of relevant past studies (U.S. Army Corps of Engineers (USACE) 1988), ${ }^{1}$ there was no way to usefully incorporate existing data into the comprehensive, system-wide information required to meet the study objectives.

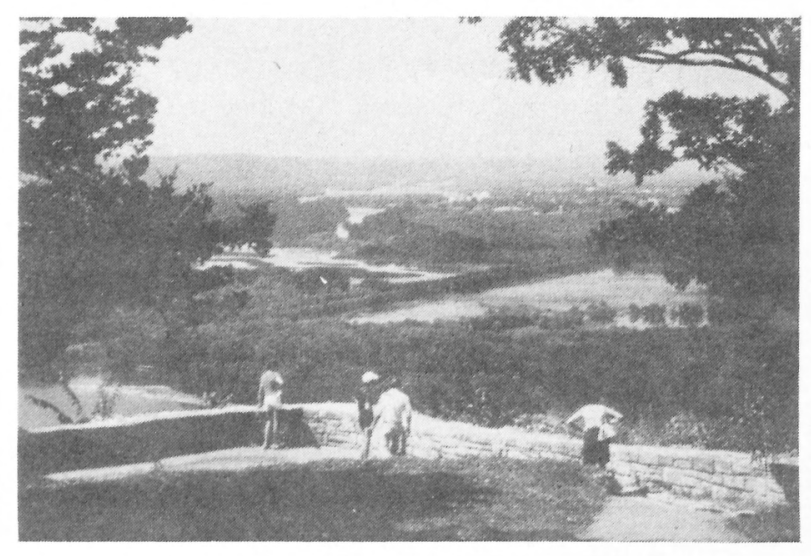

Figure 4. Recreational use associated with sightseeing areas included in scope of study
Detailed discussions of the final sampling design are contained in the sampling plan (USACE 1989). ${ }^{2}$ Existing data, study objectives, the confines of the allocated budget, and the merits of alternative measurement techniques were all considered in the development of the plan. The plan concentrated study efforts on recreational use from four types of settings: developed recreational areas; sightseeing/visitor center areas; permitted boat docks; and marina slips. These settings account for the major portions of traditional, river-based recreation

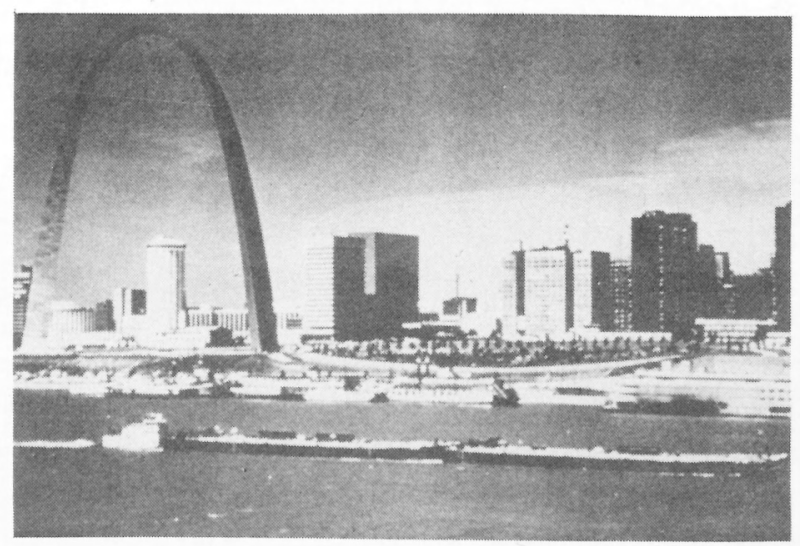

Figure 5. Some activities were not included in study, such as use of riverfront attractions

\footnotetext{
1 U.S. Army Corps of Engineers, 1988, "Recreation-economic data review, Upper Mississippi River Basin," U.S. Army Engineer Waterways Experiment Station, Vicksburg, MS, and Michigan State University, East Lansing, MI.

2 U.S. Army Corps of Engineers, 1989, "Sampling plan for the study of economic impacts of recreation in the UMRS," U.S. Army Engineer Waterways Experiment Station, Vicksburg, MS, and Michigan State University, East Lansing, MI.
} 
and account for use that would be most affected by changes in management of the river resources. Table 1 outlines the different types of recreational use that occur in the UMRS as addressed by the study.

\section{Summary of Trip Results}

More than 2.3 million recreational trips to the UMRS were made to developed areas, sightseeing/visitor center areas, marinas, and permitted boat docks during the study period. These trips were made by parties totaling nearly 6 million people (Figure 6) and equate to over 12 million daily visits of recreation. Over 60 percent of the people made their trips to developed areas (Figure 7), with the remaining trips being made to marinas (26 percent), sightseeing/visitor center areas (7 percent), and permitted docks (4 percent).

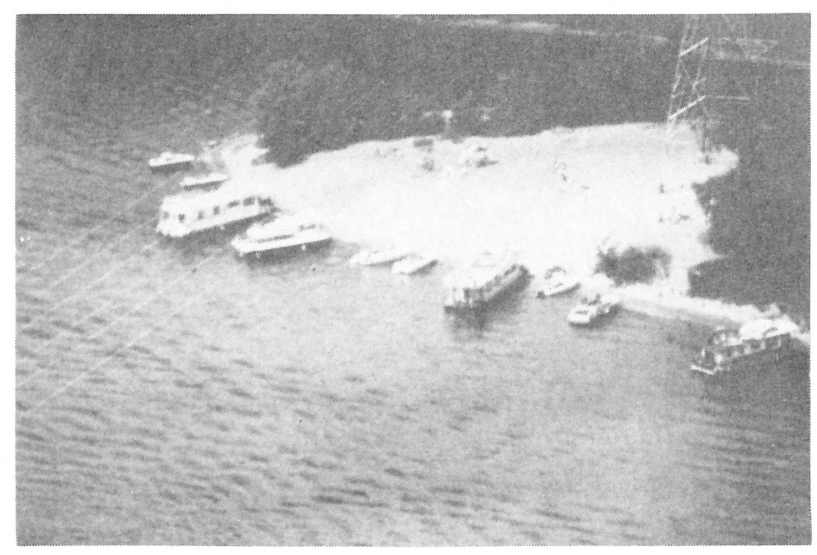

Figure 6. Boating-most popular recreational activity in the UMRS

\section{Table 1 \\ Study Treatment of UMRS Recreational Access Types}

\begin{tabular}{|c|c|c|}
\hline Type of Recreational Use & Treatment in Study & Reason for Exclusion \\
\hline Developed recreational areas & $\begin{array}{ll}\text { Included: } & \text { Sites that are used } \\
\text { primarily by sightseers. } & \\
\text { Excluded: } & \text { Recreational areas that } \\
& \text { have no vehicle access or } \\
\text { that have virtually an } & \\
\text { unlimited number of access } & \text { points. } \\
\text { Included: } & \text { All other types of } \\
\text { recreational areas that are } \\
\text { primarily accessed by } \\
\text { vehicle. }\end{array}$ & Too costly to obtain a valid sample. \\
\hline Undeveloped parking sites & Excluded & Too costly to obtain a valid sample. \\
\hline $\begin{array}{l}\text { Marinas, hunting clubs, etc., limited to } \\
\text { members only }\end{array}$ & $\begin{array}{ll}\text { Included: } & \text { Individuals who rent marina } \\
& \text { slips. } \\
\text { Excluded: Other limited membership } \\
\text { organizations. }\end{array}$ & Too costly to enumerate population. \\
\hline Riparian households & $\begin{array}{cl}\text { Included: } & \text { Households that have } \\
& \text { permits for boat docks. } \\
\text { Excluded: } & \text { Households that have no } \\
& \text { boat docks or that have } \\
& \text { nonpermitted boat docks. }\end{array}$ & $\begin{array}{l}\text { Too costly to enumerate population. } \\
\text { More boat docks expected to be per- } \\
\text { mitted by the time the sample is drawn } \\
\text { because of increased enforcement. }\end{array}$ \\
\hline Commercial boat tours & Excluded & $\begin{array}{l}\text { Likely that summary data can be } \\
\text { obtained from operators. }\end{array}$ \\
\hline Boaters who pass through the UMRS & Excluded & Too costly to obtain valid sample. \\
\hline $\begin{array}{l}\text { River festivals, fishing tournaments, } \\
\text { etc. }\end{array}$ & Excluded & $\begin{array}{l}\text { Likely that summary data can be } \\
\text { obtained from activity organizers. }\end{array}$ \\
\hline
\end{tabular}




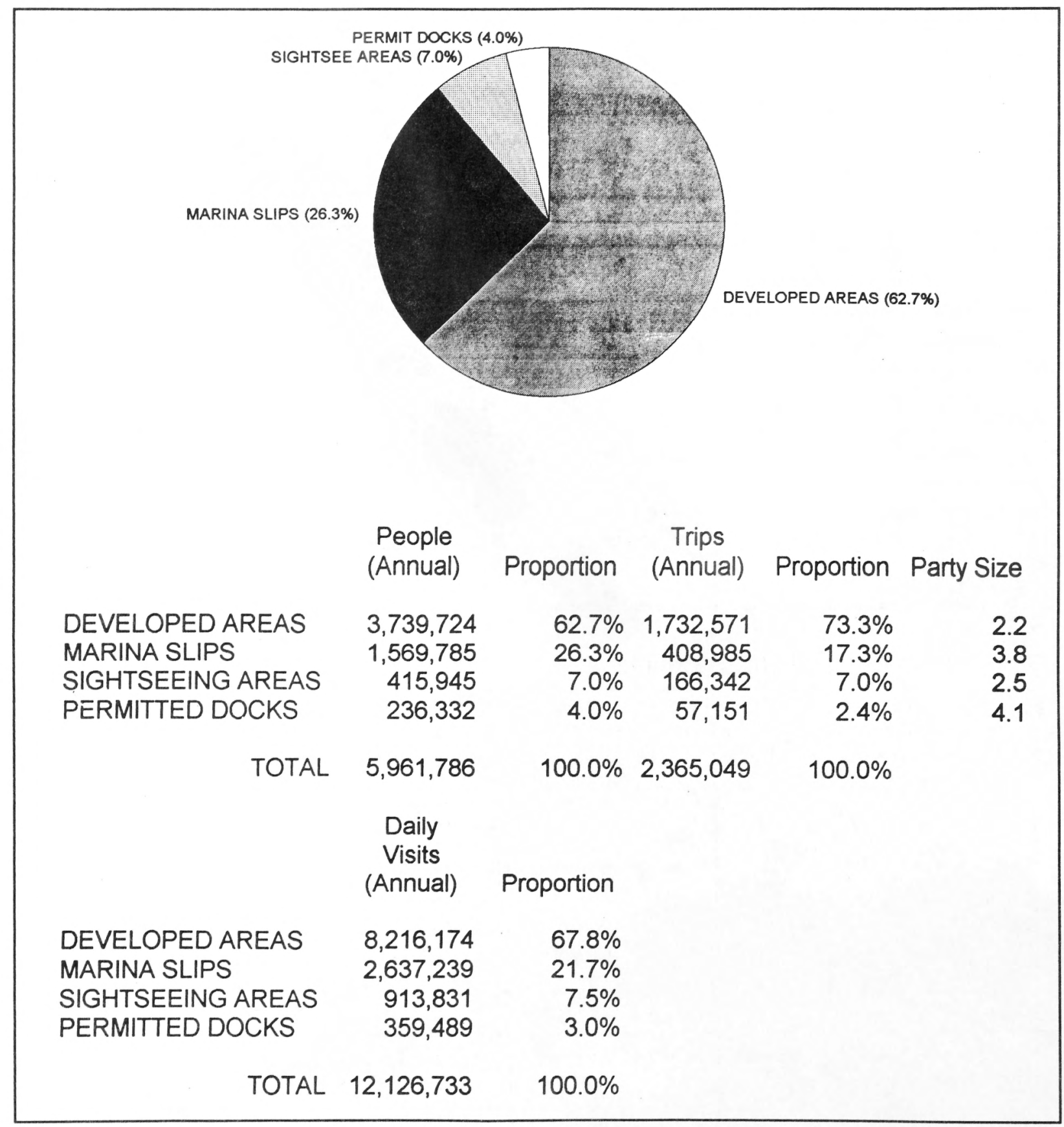

Figure 7. Recreational use of UMRS by access type (people)

Residents of the UMRS accounted for the majority of the trips, ranging from two-thirds to three-fourths for all types of access. Single day trips were predominant (around 75 percent) when compared with trips including overnight stays. Average party sizes were larger for trips to permitted docks and marinas.
For developed areas, in which use was distinguished by four regions, the vast majority of the use ( 86 percent) took place in the St. Paul and Rock Island stretches of the UMRS. Only system-wide estimates are available for the sightseeing/visitor center areas, marina, and boat dock surveys, so 
regional distribution of use cannot be reported.

\section{Summary of Activity Results}

The largest single activity among visitors to the UMRS was boating, in which over one-half of all visitors participated (Figure 8). Boating activities included recreational boating, boat fishing, and waterskiing. For the developed sites, comparing by region, boating was the dominant activity in all areas except Region 2, where sightseeing (only) accounted for the largest number of people (42 percent, compared with 28 percent boating). Sightseeing (only) was also the most common activity among visitors to the sightseeing/visitor center areas.
The largest nonboating activity for all visitors was sightseeing only, which accounted for roughly one-fifth of all visitors. The only other activity in which nearly 10 percent of visitors participated was fishing from shore.

The estimates for total trips and total visitors have associated errors under 10 percent for all surveys except the sightseeing/visitor center areas (under 20 percent). For the regional estimates in the developed areas survey, use in the St. Louis and Illinois River stretches proved to be highly variable, characterized by many sites having little or no use and other sites having comparatively high use. Confidence in the tallies for these regions is consequently lower than those for the other two regions and for the study area as a whole.

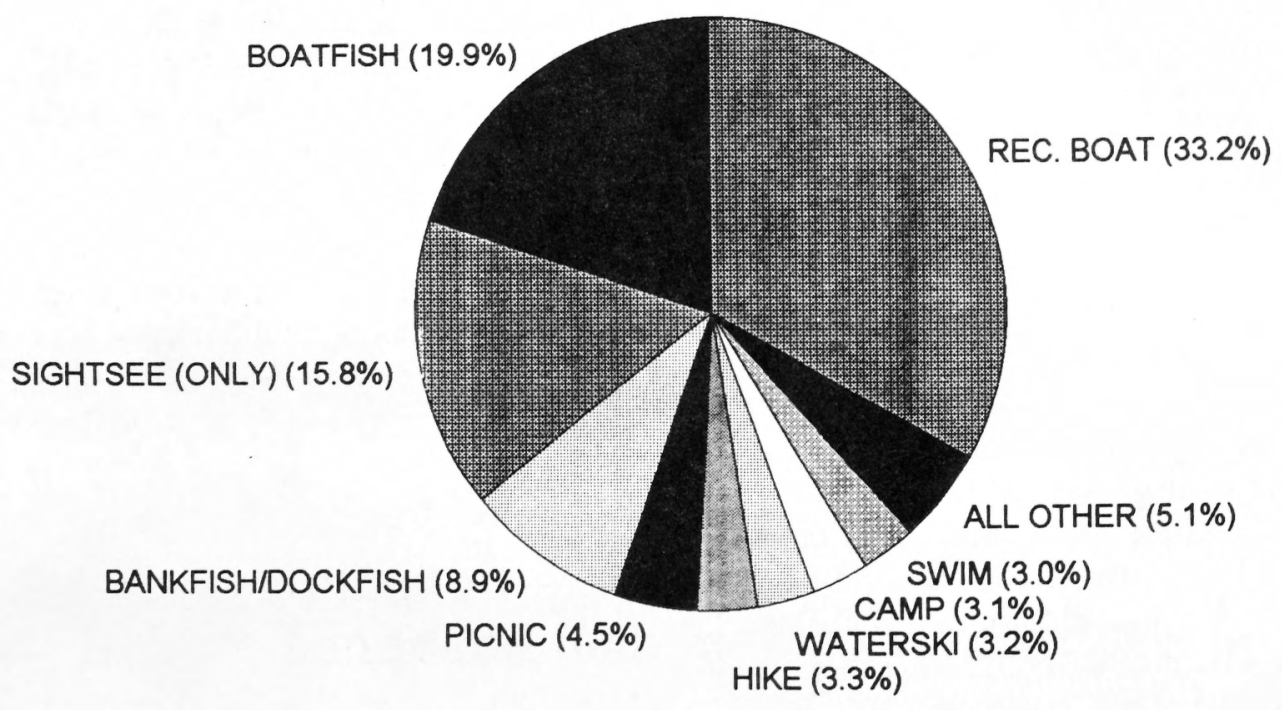

Figure 8. Activities breakdown, all surveys (sum of annual totals) 


\section{Survey of Developed Recreational Areas and Sightseeing Areas}

\section{Methods}

Measurement of use at the developed recreational areas and sightseeing areas/visitor centers was done through the use of on-site traffic stop surveys. A stratified random approach was used in drawing the sample of sites to be surveyed. Five levels of strata were used: geographic region, season of the year, level of anticipated use, day of the week, and time of day.

The four geographic regions were selected to allow comparisons between different parts of the system. The regions divide the study area into nearly equal stretches of approximately 300 river miles each. Three of the four regions conform to Corps of Engineers District boundaries: Region 1, in the St. Paul District, covers the Mississippi River from river mile 614 to the northernmost part of the study area (Minneapolis, river mile 857.6), plus the Black, St. Croix, and Minnesota Rivers; Region 2, in the Rock Island District, covers the Mississippi River between river miles 300 and 614; and Region 3, in the St. Louis District, covers the Mississippi River from river mile 300 south to Cairo, IL (river mile 0), plus the Kaskaskia River. The fourth region covers the Illinois River from Lockport, IL, to the confluence of the Illinois and Mississippi Rivers. Note that Region 4 also falls under the jurisdiction of the Rock Island District but has been separated for the purposes of use estimation.
Scenic overlooks, sightseeing areas, and visitor centers along the river corridors were also identified and surveyed. These sites were sampled separately from the on-river sites and were not distinguished by geographic region.

A total of 597 sites were included in the developed recreational area survey: 257 in Region 1; 199 in Region 2; 68 in Region 3; and 73 in Region 4 . There were 44 sites throughout the system that were included in the sightseeing/visitor center survey. A total of 240 sampling periods were completed for the developed sites, and 60 sampling periods were completed for the sightseeing areas. These surveys were conducted between November 1989 and November 1990 and resulted in over 1,300 interviews with recreational visitors.

\section{Data Collection and Response}

A total of 1,316 completed interviews were collected during this part of the study. The interviews were completed during 300 scheduled sampling periods. There was no recreational use reported for 95 of the 300 sampling periods.

Data from the on-site interviews were coded on paper questionnaires and transferred to DBASEIII format by a contractor for the Government. Data verification routines and 
logical checks were programmed and used to meet data integrity specifications of the scope of work. After submittal, the data were checked by the Government for any inconsistencies or logical errors, as well as for compliance with the specifications in the sampling plan. Any anomalies discovered were corrected by comparing the data in question with monthly and seasonal reports and other corroborating data.

\section{Results}

\section{Trip and activity estimates-UMRS total}

There were over 1.9 million trips by parties of recreational visitors to developed recreational areas and sightseeing areas/visitor center areas during the study period. These trips were made by over 4.1 million visitors. Over 90 percent of this use was associated with sites with direct river access, with the remaining 10 percent attributable to sightseeing areas.

The vast majority of this use ( 86 percent) took place in the St. Paul and Rock Island stretches of the UMRS (Regions 1 and 2). A breakdown of visitors by region is shown in Figure 9. A summary of the estimated trip and visitor counts is also included in Table 2 accompanying Figure 9. (Visitors to the sightseeing areas/visitor centers are not represented in the pie chart, since region was not distinguished for those sites. They are included in the numerical summary for completeness.)

Boating was the most common activity for visitors to the developed river sites, with nearly half (47 percent) of all visitors participating. Boat fishing was most common (34 percent), followed by recreational boating ( 20 percent) and waterskiing ( 3 percent). It is evident that some individuals participated in more than one of these activities, since the sum of the separate boating activities exceeds the total. This is possible under circumstances where a visitor participated in multiple activities during a given outing, or where a visitor took an extended trip that included several different types of outings. Boaters may also have participated in nonboating activities on their trips, and these activities have been recorded as well.

The most common nonboating activity measured was sightseeing ( 26 percent), which was counted as an activity only when mentioned by survey respondents and when no other activities were mentioned.

Bank fishing (15 percent) was the other most common activity. Camping, hiking, and picnicking were each undertaken by approximately 5 percent of all visitors. All other activities measured had less than 5-percent participation.

Estimates of the total number of trips, visitors, and recreational activities engaged in during trips are displayed in Table 2 for the four regions combined (UMRS total). Activities in the table are listed in descending order of total participation. The percent of the total number of people who participated in a given activity follows the estimated total for each activity, along with the variance, standard deviation, degrees of freedom (DF) and t-score, the upper and lower confidence limits (UCL and LCL) (computed at 90-percent confidence), and the percent error in the estimate.

A breakdown of activities engaged in is displayed in Figure 10. The sections of the pie chart represent the proportion of a given activity in comparison with the total of all activities participated in. This statistic differs from the percentage of all persons who engaged in a given activity, which is contained in Table 2.

Figure 10 depicts the estimated means and associated confidence limits for each activity. The number for each point has been taken from Table 2. As presented, there is a 90-percent certainty that the true mean for each activity falls within the upper and lower confidence limits shown. (The lines connecting the points are for illustrative purposes only, since no relationship exists between the points for various activities.) 


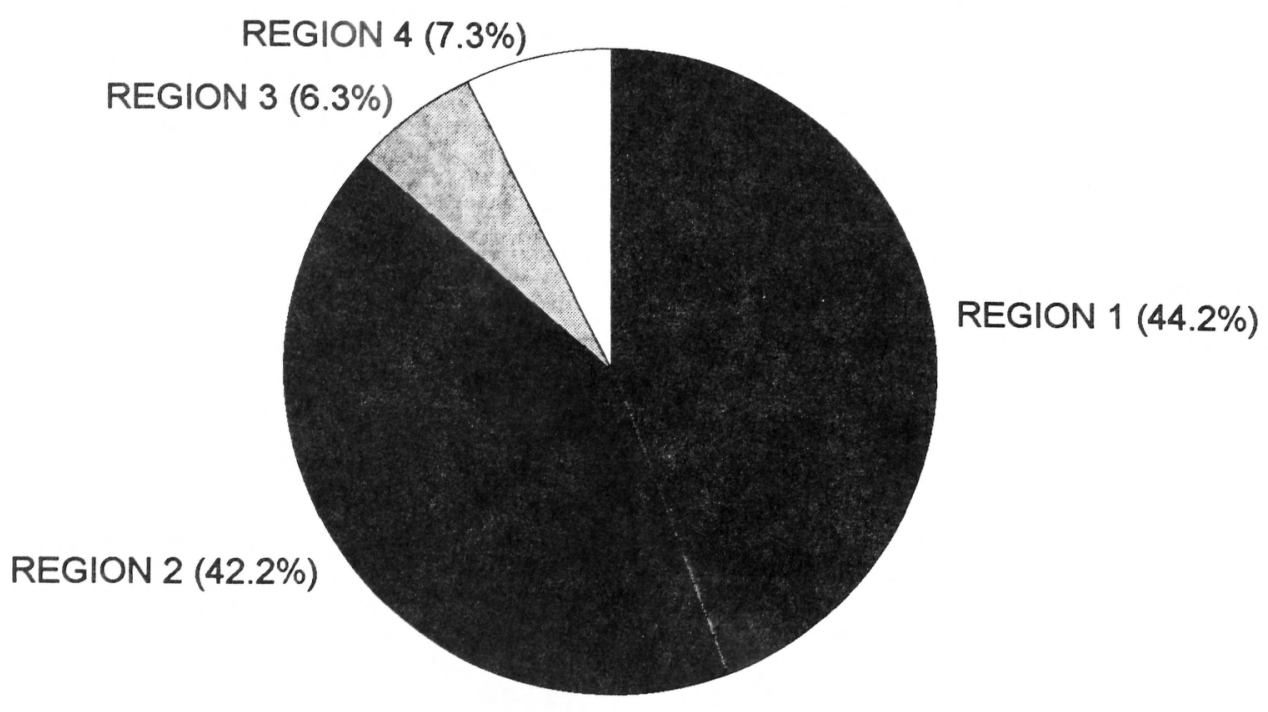

People

(Annual) Proportion
Trips

(Annual) Proportion Party Size
REGION 1 1,652,853

REGION 2

REGION 3

REGION 4

SUBTOTAL

SIGHTSEE

$1,576,994$

235,719

274,158

$3,739,724$

415,945

$44.2 \%$

$42.2 \%$

$6.3 \%$

$7.3 \%$

$100.0 \%$

699159
816755
106105
110552

$40.4 \%$

$47.1 \%$

$6.1 \%$

$6.4 \%$

2.2

2.5
$1,732,571$
166,342

$100.0 \%$

2.2

$9.6 \%$

2.5

TOTAL

$4,155,669$

$109.6 \%$

2.2

Figure 9. Recreational use of developed sites by region (people)

Trip and activity estimates-individual regions

Individual trip, visitation, and activity counts have been computed for each of the four regions in a manner that duplicates the region-wide estimates. The estimates are presented separately in Figures 11 through 14, respectively. Estimates for sightseeing areas/visitor centers have also been prepared in this manner and are presented in the next section.

Some differences are evident in the types of activities occurring in the regions. For example, boating activities are predominant in Regions 1, 3, and 4, but sightseeing dominates in Region 2. Sightseeing was also a common activity in Region 3, but was less prevalent in Region 4 and Region 1. 
Table 2
Recreational Trip and Activity Estimates, UMRS Total (Regions 1-4)

\begin{tabular}{|c|c|c|c|c|c|c|c|c|c|}
\hline & Totals & $\begin{array}{l}\% \text { of } \\
\text { People }\end{array}$ & Variance & $\begin{array}{l}\text { Standard } \\
\text { Deviation }\end{array}$ & DF & $\begin{array}{l}90 \% \\
\text { t-Score }\end{array}$ & LCL & UCL & $\begin{array}{l}\% \\
\text { Error }\end{array}$ \\
\hline Total trips & $1,732,571$ & & $25,365,216,256$ & 159,265 & 15 & 1.753 & $1,453,381$ & $2,011,763$ & 9.2 \\
\hline Total people & $3,739,724$ & & $122,831,249,587$ & 350,473 & 14 & 1.761 & $31,122,541$ & $4,356,907$ & 9.4 \\
\hline Total boaters & $1,764,450$ & 47 & $37,711,365,231$ & 194,194 & 12 & 1.782 & $1,418,396$ & $2,110,504$ & 11.0 \\
\hline Boatfish & $1,264,229$ & 34 & $33,460,154,030$ & 182,921 & 5 & 2.015 & 895,643 & $1,632,815$ & 14.5 \\
\hline Sightsee (only) & 955,298 & 26 & $24,425,387,345$ & 156,286 & 9 & 1.833 & 668,825 & $1,241,771$ & 16.4 \\
\hline Rec. boat & 749,616 & 20 & $21,406,261,270$ & 146,309 & 8 & 1.86 & 477,482 & $1,021,751$ & 19.5 \\
\hline Bankfish & 562,052 & 15 & $12,846,651,043$ & 113,343 & 9 & 1.833 & 354,294 & 769,809 & 20.2 \\
\hline Camp & 199,010 & 5 & $3,012,582,470$ & 54,887 & 8 & 1.86 & 96,920 & 301,100 & 27.6 \\
\hline Hike & 173,892 & 5 & $2,090,407,644$ & 45,721 & 8 & 1.86 & 88,851 & 258,933 & 26.3 \\
\hline Picnic & 139,329 & 4 & $2,749,690,105$ & 52,437 & 5 & 2.015 & 33,667 & 244,990 & 37.6 \\
\hline Duck hunt (bank) & 121,897 & 3 & $4,604,610,115$ & 67,857 & 3 & 2.353 & 0 & 281,565 & 55.7 \\
\hline Waterski & 112,638 & 3 & $1,527,706,161$ & 39,086 & 4 & 2.132 & 29,307 & 195,970 & 34.7 \\
\hline Misc & 84,102 & 2 & $742,249,409$ & 27,244 & 8 & 1.86 & 33,428 & 134,776 & 32.4 \\
\hline Swim & 67,871 & 2 & $614,321,057$ & 24,786 & 6 & 1.943 & 19,713 & 116,029 & 36.5 \\
\hline Socialize & 17,869 & 0 & $66,876,544$ & 8,178 & 7 & 1.895 & 2,372 & 33,366 & 45.8 \\
\hline Gathering & 17,388 & 0 & $123,608,984$ & 11,118 & 4 & 2.132 & 0 & 41,091 & 63.9 \\
\hline Bird watch & 14,751 & 0 & $85,101,936$ & 9,225 & 3 & 2.353 & 0 & 36,457 & 62.5 \\
\hline Small game & 7,605 & 0 & $31,001,676$ & 5,568 & 2 & 2.92 & 0 & 23,863 & 73.2 \\
\hline Icefish & 3,743 & 0 & $5,659,974$ & 2,379 & 4 & 2.132 & 0 & 8,815 & 63.6 \\
\hline Cross-country skiing & 0 & 0 & 0 & 0 & & & 0 & 0 & 0.0 \\
\hline Snowmobile & 0 & 0 & 0 & 0 & & & 0 & 0 & 0.0 \\
\hline Big game & 0 & 0 & 0 & 0 & & & 0 & 0 & 0.0 \\
\hline
\end{tabular}




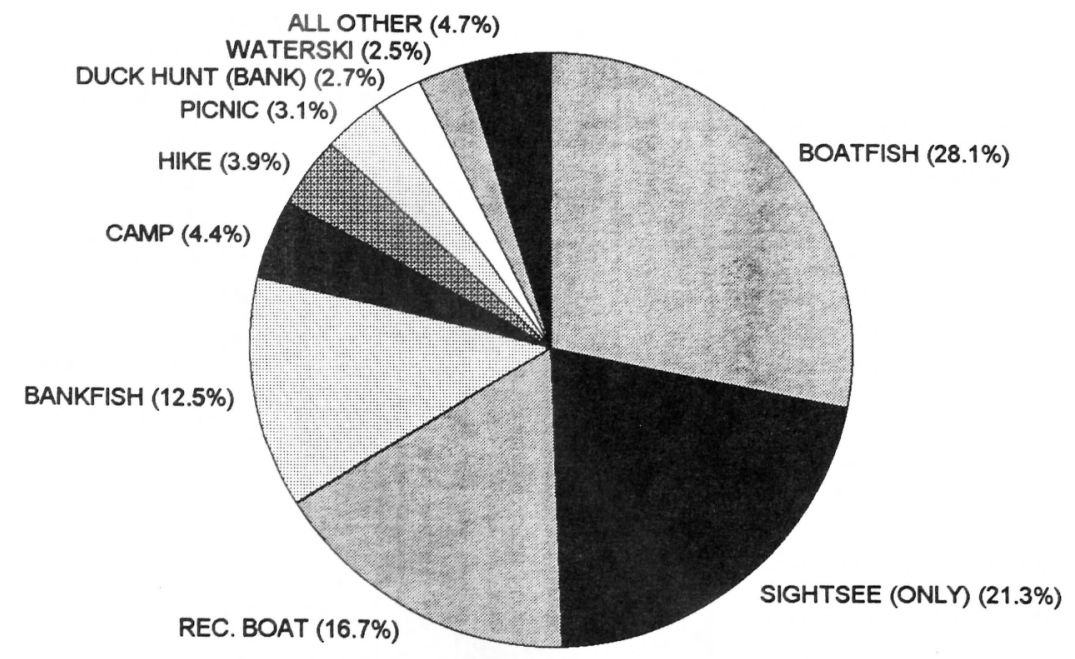

a. Activities breakdown

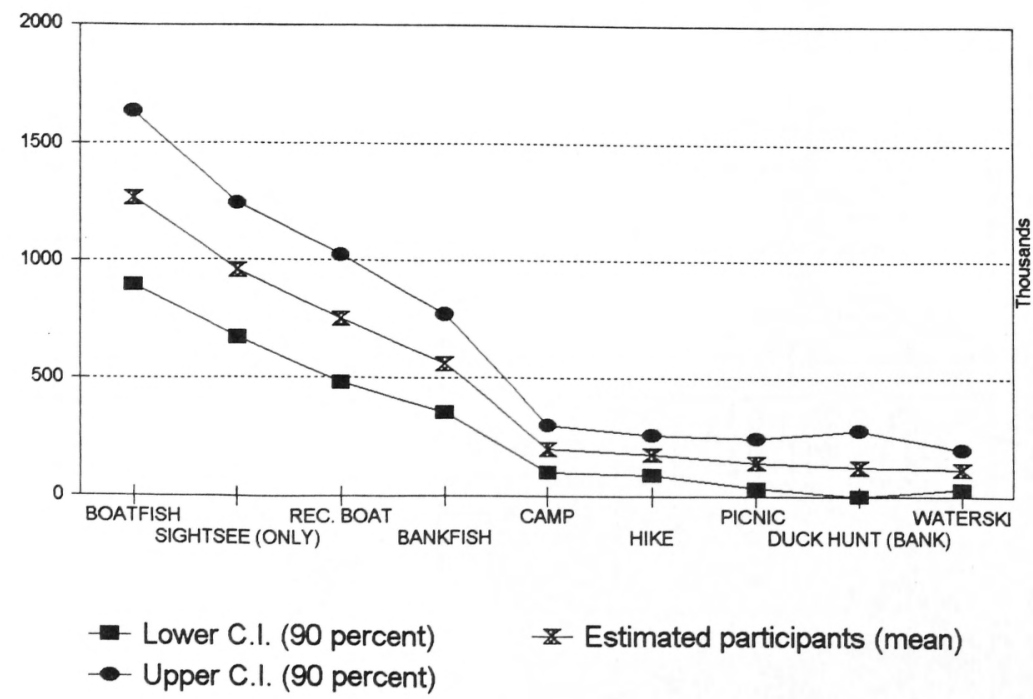

b. Activity estimates and confidence intervals

Figure 10. UMRS total (Regions 1-4) 


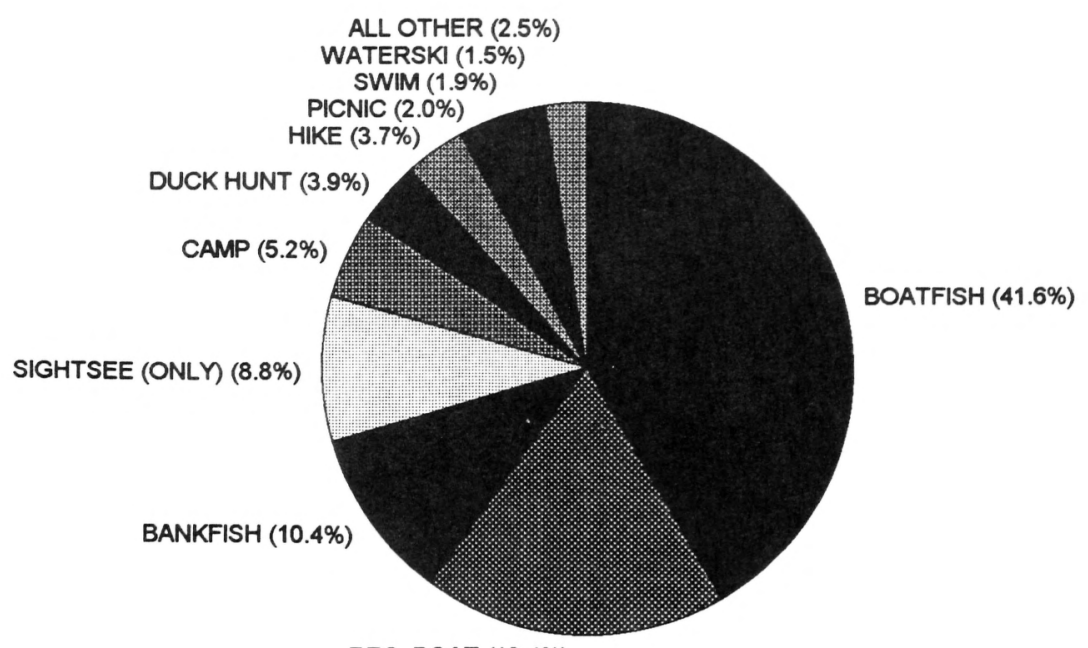

REC. BOAT (18.4\%)

Figure 11. Activities breakdown, Region 1

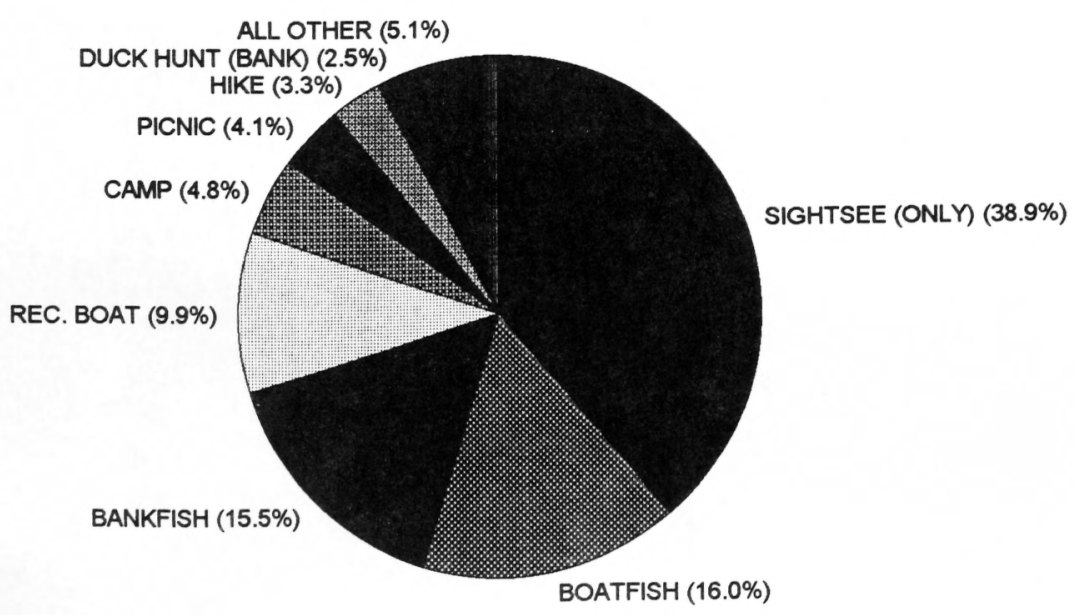

Figure 12. Activities breakdown, Region 2 


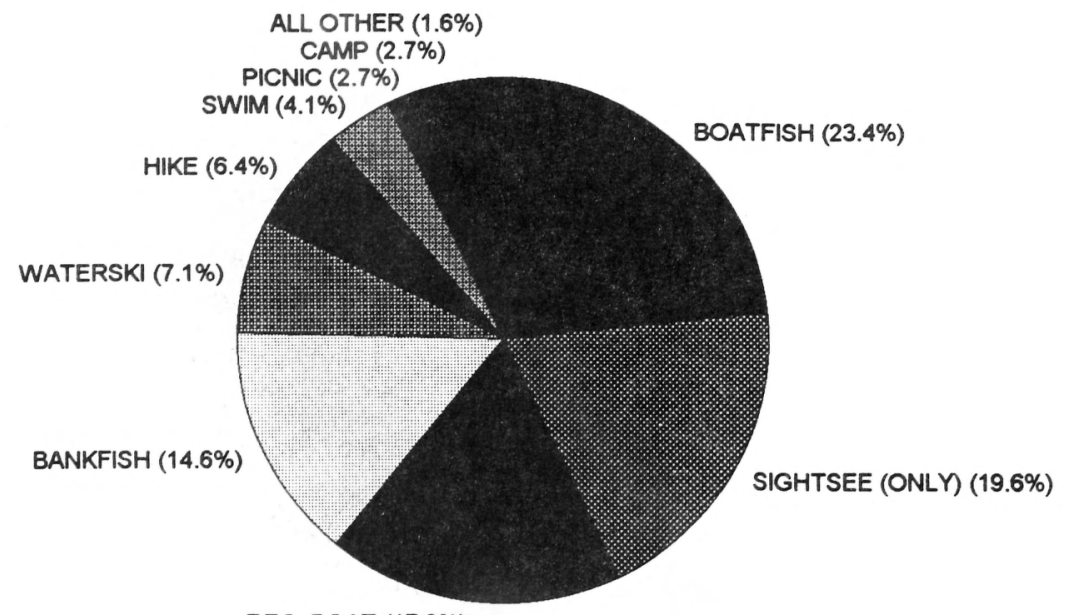

REC. BOAT (17.9\%)

Figure 13. Activities breakdown, Region 3

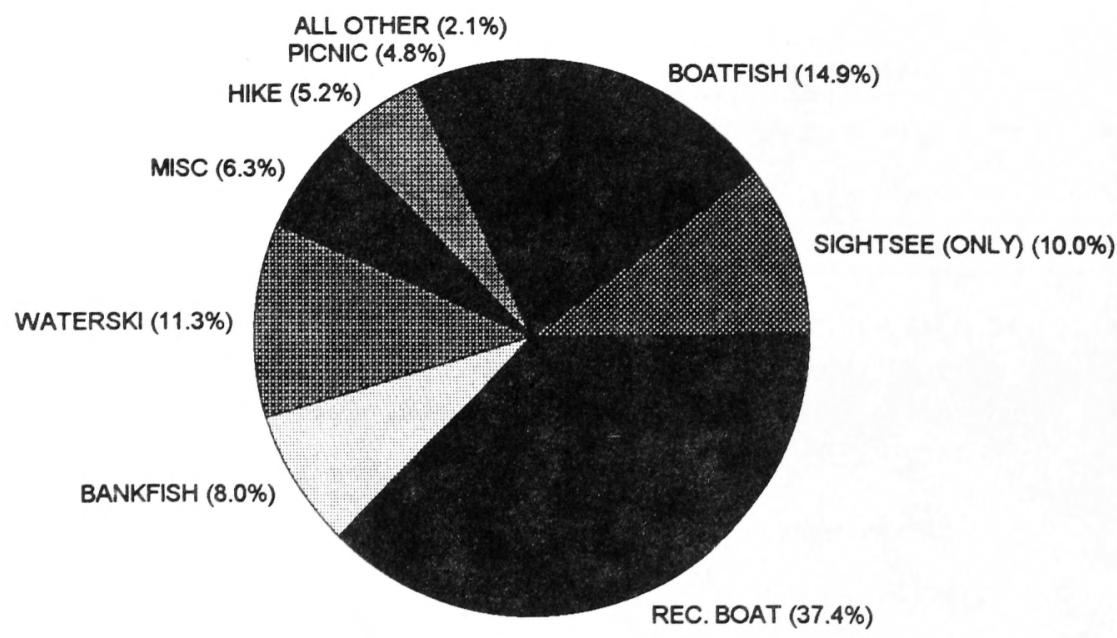

Figure 14. Activities breakdown, Region 4 
A cautionary note is warranted regarding making comparisons between the regions, since the quality of many of the estimates at the regional level is limited. The quality of the estimates varies by region, as well as between the more common and less common activities. In general, the estimates for activities in Regions 1 and 2 show much less variation than those in Regions 3 and 4. Still, the percent error (standard deviation divided by the mean) exceeds 50 percent for some estimates in all regions, especially for low-participation activities.

\section{Activity estimates-sightseeing areas/visitor centers}

Nearly one-half of the visitors to the sightseeing areas and visitor centers participated in sightseeing only on their trip to the UMRS. Another 30 percent participated in boating activities. Hiking, picnicking, swimming, and bank fishing were the other most common activities (10- to 15-percent participation) reported by visitors to these areas.

The activity estimates for visitors to these areas vary considerably in the amount of associated error. Similar to Regions 3 and 4, the sightseeing areas had a relatively high proportion of zero observation periods ( 21 out of 60 periods showed zero recreational use). The computed estimates and associated figures are presented in Table 3 and in Figures $15 \mathrm{a}$ and $\mathrm{b}$. 


\section{Table 3 \\ Recreational Trip and Activity Estimates, Sightseeing Areas/Visitor Centers}

\begin{tabular}{|c|c|c|c|c|c|c|c|c|c|}
\hline & Totals & $\begin{array}{l}\text { \% of } \\
\text { People }\end{array}$ & Variance & $\begin{array}{l}\text { Standard } \\
\text { Deviation }\end{array}$ & DF & $\begin{array}{l}90 \% \\
\text { t-Score }\end{array}$ & LCL & UCL & $\begin{array}{l}\% \\
\text { Error }\end{array}$ \\
\hline Total trips & 166,342 & & $575,827,691$ & 23,996 & 14 & 1.761 & 124,085 & 208,600 & 14.4 \\
\hline Total people & 415,945 & & $6,539,655,963$ & 80,868 & 6 & 1.943 & 258,818 & 573,072 & 19.4 \\
\hline Total boaters & 120,783 & 29 & $6,869,694,959$ & 82,884 & 3 & 2.353 & 0 & 315,808 & 68.6 \\
\hline Sightsee (only) & 196,543 & 47 & $1,997,248,000$ & 44,691 & 6 & .1 .943 & 109,709 & 283,376 & 22.7 \\
\hline Rec. Boat & 97,110 & 23 & $6,404,711,612$ & 80,029 & 3 & 2.353 & 0 & 285,419 & 82.4 \\
\hline Hike & 63,631 & 15 & $841,765,878$ & 29,013 & 4 & 2.132 & 1,775 & 125,487 & 45.6 \\
\hline Swim & 62,121 & 15 & $3,305,514,506$ & 57,494 & 3 & 2.353 & 0 & 197,403 & 92.6 \\
\hline Picnic & 53,253 & 13 & $2,335,509,912$ & 48,327 & 3 & 2.353 & 0 & 166,967 & 90.7 \\
\hline Bankfish & 32,742 & 8 & $282,896,080$ & 16,820 & 4 & 2.132 & 0 & 68,601 & 51.4 \\
\hline Boatfish & 32,066 & 8 & $192,212,269$ & 13,864 & 5 & 2.015 & 4,130 & 60,002 & 43.2 \\
\hline Big game & 11,125 & 3 & $123,431,885$ & 11,110 & 3 & 2.353 & 0 & 37,266 & 99.9 \\
\hline Bird watch & 10,095 & 2 & $65,986,177$ & 8,123 & 7 & 1.895 & 0 & 25,488 & 80.5 \\
\hline Camp & 7,705 & 2 & $26,043,493$ & 5,103 & 5 & 2.015 & 0 & 17,988 & 66.2 \\
\hline Misc & 5,272 & 1 & $7,699,393$ & 2,775 & 9 & 1.833 & 186 & 10,358 & 52.6 \\
\hline Waterski & 3,777 & 1 & $14,211,276$ & 3,770 & 3 & 2.353 & 0 & 12,647 & 99.8 \\
\hline Duck hunt (bank) & 3,178 & 1 & $5,165,533$ & 2,273 & 10 & 1.812 & 0 & 7,296 & 71.5 \\
\hline Socialize & 2,227 & 1 & $2,844,445$ & 1,687 & 4 & 2.132 & 0 & 5,823 & 75.7 \\
\hline Gathering & 1,496 & 0 & $2,230,700$ & 1,494 & 3 & 2.353 & 0 & 5,011 & 99.8 \\
\hline Icefish & 505 & 0 & 252,313 & 502 & 7 & 1.895 & 0 & 1,456 & 99.6 \\
\hline Cross-country skiing & 0 & 0 & 0 & 0 & & & 0 & 0 & 0.0 \\
\hline Snowmobile & 0 & 0 & 0 & 0 & & & 0 & 0 & 0.0 \\
\hline Small game & 0 & 0 & 0 & 0 & & & 0 & 0 & 0.0 \\
\hline
\end{tabular}




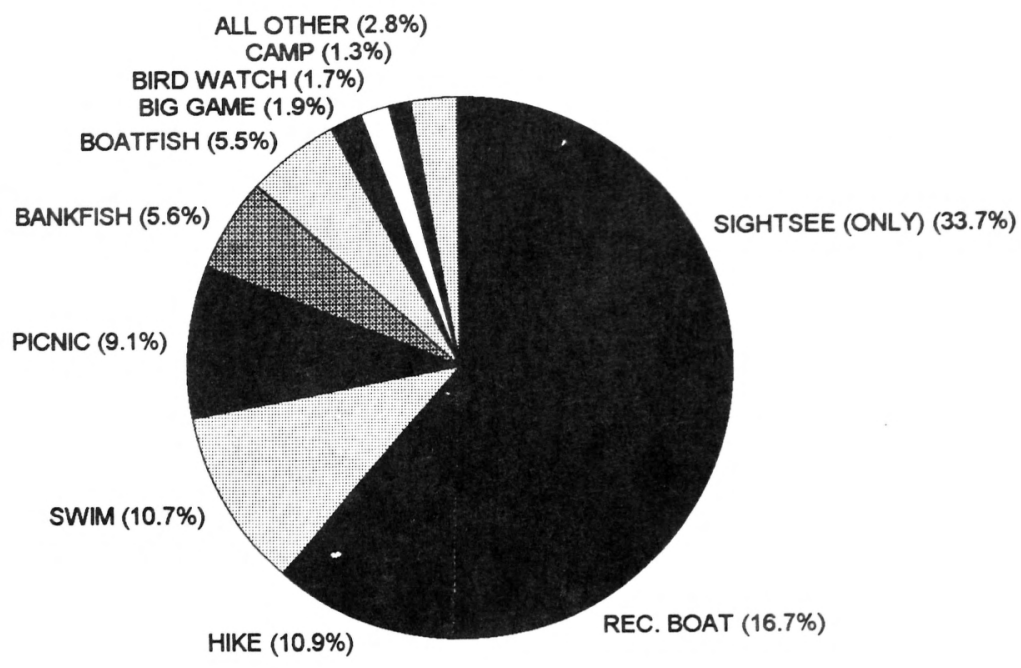

a. Activities breakdown

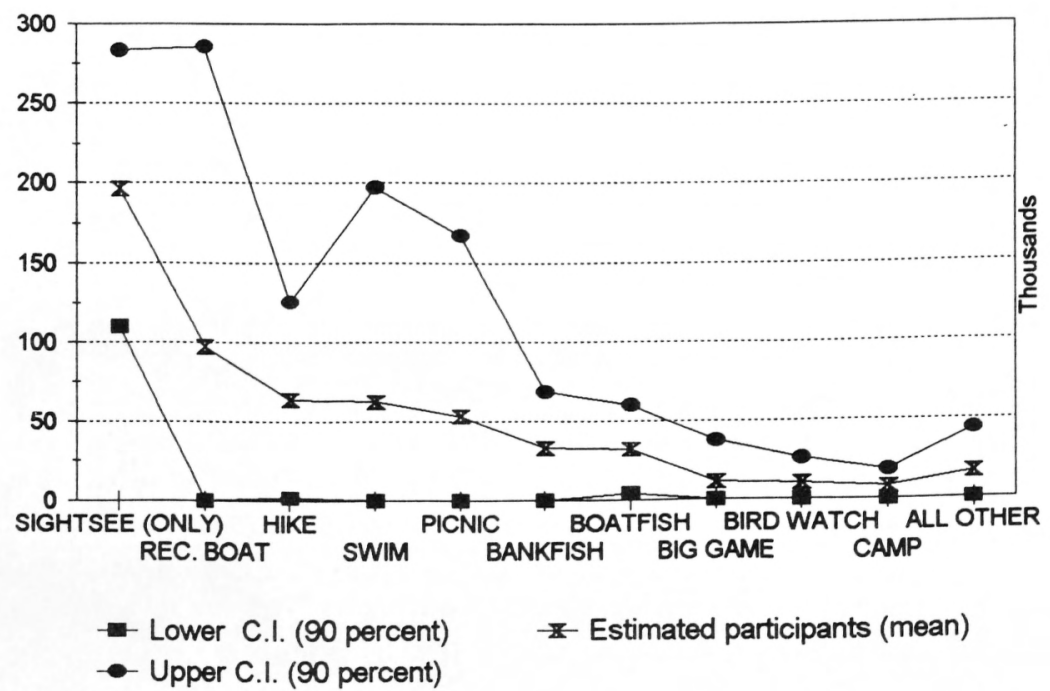

b. Activity estimates and confidence intervals

Figure 15. Activity estimates—sightseeing areas/visitor centers 


\section{Survey of Permitted Dock Owners}

\section{Methods}

Recreational use of permitted boat docks was measured through the use of a telephone survey. The survey included a sample of 150 households randomly selected from approximately 2,800 households in the study area. These households had Section 404 permits authorized under the Clean Water Act or special-use permits required for docks located on Government land.

An initial "profile" interview was conducted to confirm that the boat dock was used for recreation, to gather household and durable goods information, and to seek further participation in the year-long study. Participants were contacted by telephone at 10 randomly selected times during the year to determine recreational trips and associated activities they participated in during the preceding week. Three contacts each were made during spring, summer, and fall, with the remaining contact made during winter. Expenditures related to the recreational trips were reported through use of a mailback questionnaire.

\section{Data Collection and Response}

A total of 1,650 telephone interviews were scheduled during the survey year: 150 "profile" interviews and 1,500 "follow-up" calls to gather trip and activities information. Table 3 summarizes the response rate to the survey.

All 150 "profile" interviews were completed to establish the sample. A total of 1,419 calls were completed in the "follow-up" use survey.

\section{Results}

Nearly a quarter-million people $(236,332)$ participated in over 57,000 trips originating from permitted docks along the UMRS during the year surveyed. Over one-half of this use ( 57 percent) took place during the summer season. Recreational use was almost equally divided among the remaining seasons, each ranging from 13 to 16 percent of the annual total. A seasonal breakdown of use from permitted boat docks is shown on Figure 16, along with a summary of the trip and visitor counts that have been estimated.

Recreational boating was the most common activity reported (37 percent of all persons), closely followed by boat fishing (33 percent of all persons). Other common activities included fishing from a dock (22 percent), swimming (17 percent), picnicking (13 percent), and waterskiing (11 percent). Activities that had participation under 10 percent included ice fishing, duck hunting, cross-country skiing, camping, and miscellaneous activities. 


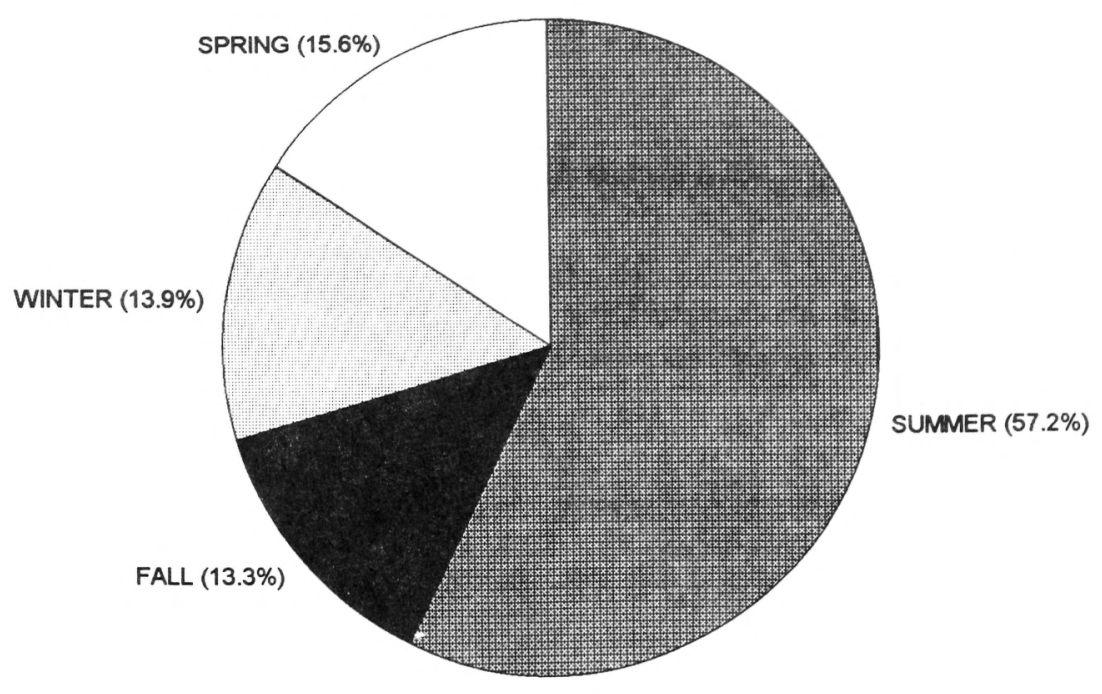

People Proportion Trips Proportion Party Size

$\begin{array}{lrrrrr}\text { SUMMER } & 135,243 & 57.2 \% & 31,508 & 55.1 \% & 4.3 \\ \text { FALL } & 31,329 & 13.3 \% & 8,252 & 14.4 \% & 3.8 \\ \text { WINTER } & 32,897 & 13.9 \% & 5,921 & 10.4 \% & 5.6 \\ \text { SPRING } & 36,863 & 15.6 \% & 11,470 & 20.1 \% & 3.2\end{array}$

$\begin{array}{llllll}\text { TOTAL } & 236,332 & 100.0 \% & 57,151 & 100.0 \% & 4.1\end{array}$

Figure 16. Recreational use of permitted docks by season (people)

Annual estimates for the number of trips, visitors, and recreational activities engaged in during trips are displayed in Table 4. Activities in the table are listed in descending order of participation. For the permitted dock survey, the UCL and LCL have been computed at the level of 95 -percent confidence.

Figures $17 \mathrm{a}$ and $\mathrm{b}$ illustrate the breakdown of activities engaged in during the study pe- riod. Sections of the pie chart represent the proportion of a given activity in comparison with the total of all activities. Activities with small percentages have been combined and identified as "other." Miscellaneous activities that were identified by respondents have also been included in an aggregated category. 
Table 4

Recreational Trip and Activity Estimates, Permitted Docks (Annual: 1990-91)

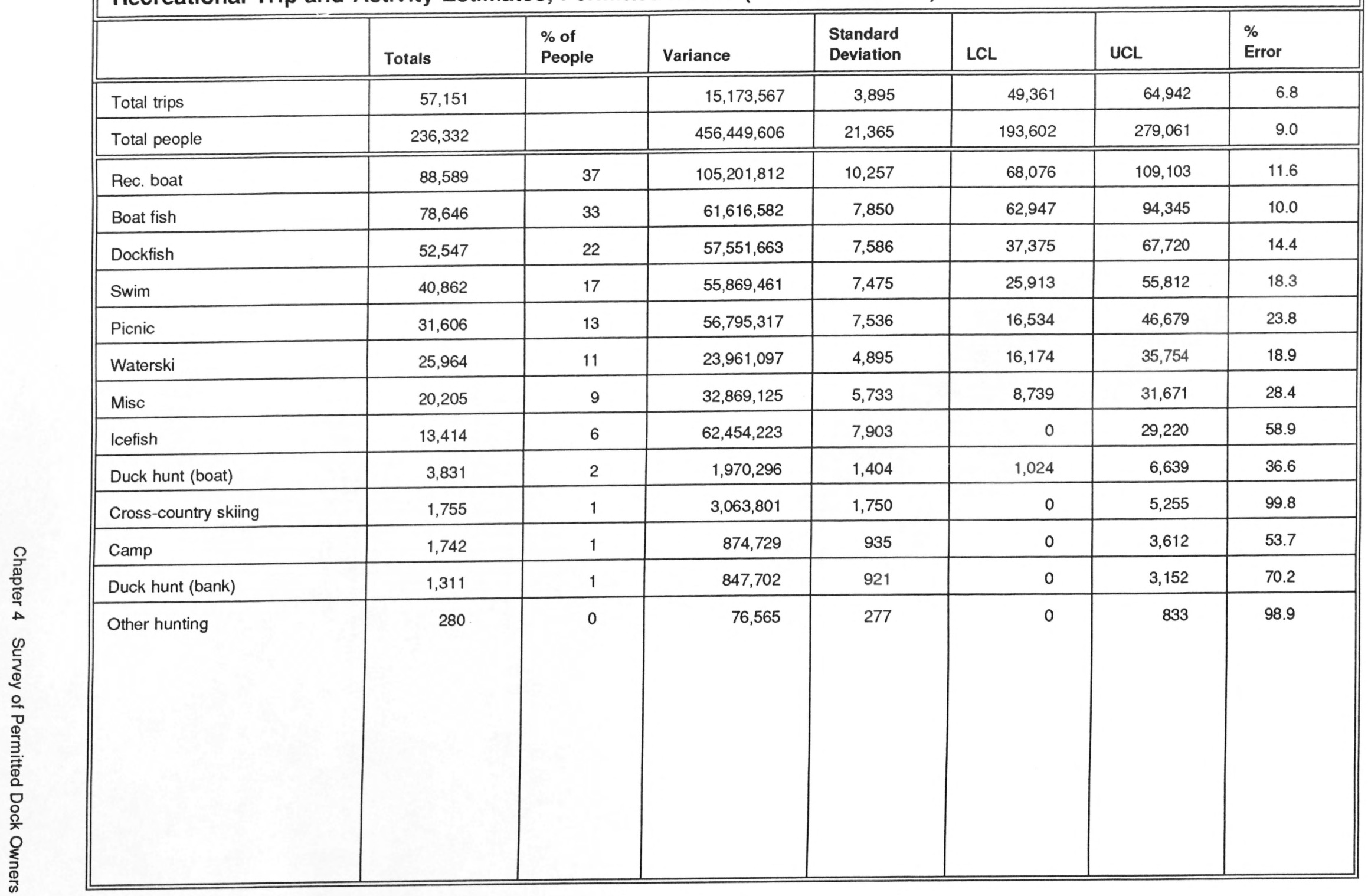




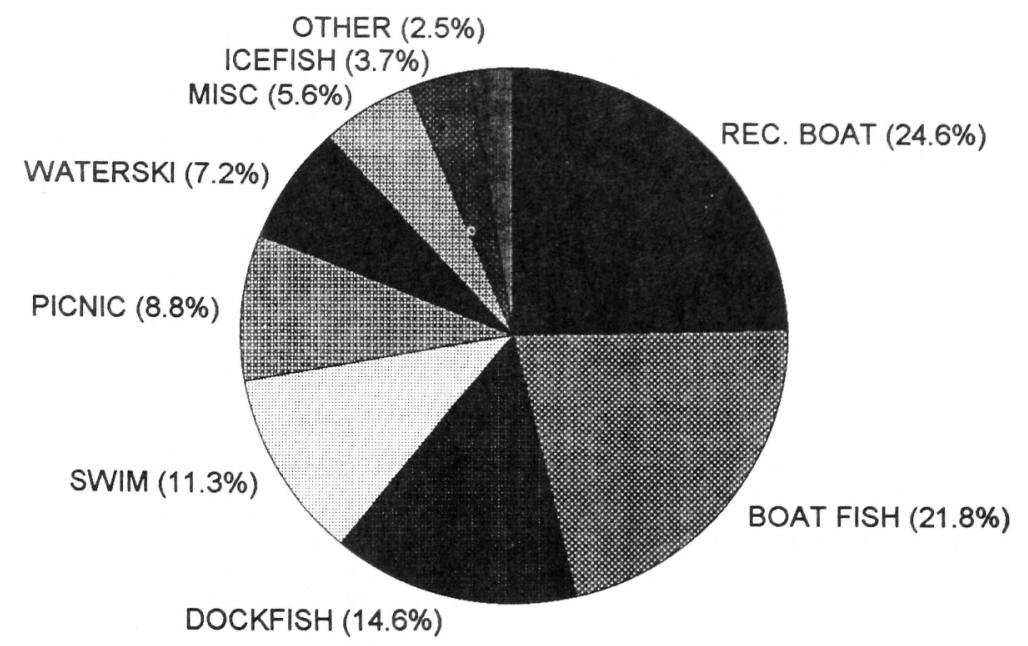

a. Activities breakdown

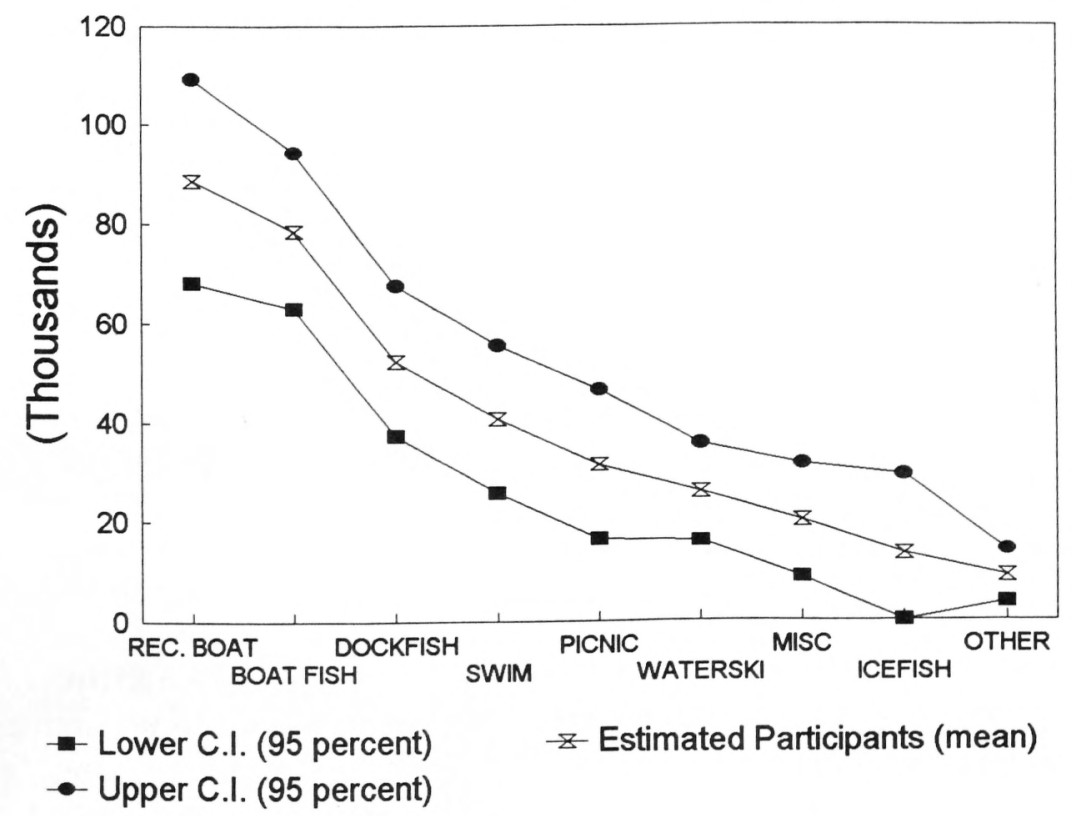

b. Activity estimates and confidence intervals

Figure 17. Permitted docks (annual total, 1990-1991) 


\section{Survey of Marina Slip Renters/Owners}

\section{Methods}

Measurement of use from marina slips was done through a telephone survey to a sample of 150 households who were called at random times throughout the boating season. The households were selected randomly from the over 18,000 slips contained in 209 marinas in the study area. Each household was contacted for an initial "profile" interview to gather household and durable goods information, and was then contacted during nine randomly selected weeks to document the previous week's recreational use and activities. The calls were stratified by season, resulting in three calls each during spring, summer, and fall. Mailback questionnaires were used to log recreational trip related expenses that were made during the weeks sampled.

\section{Data Collection and Response}

A total of 1,500 telephone interviews were scheduled for the survey: 150 "profile" intervicws and 1,350 "follow-up" calls to gather information on recreational trips. A total of 151 "profile" calls were completed in establishing the sample. A summary of the response rate to the marina survey is contained in Table 5.
A total of 1,019 "follow-up" calls were completed. Of the remaining calls, 219 were not completed because there was no answer by the household after repeated attempts, 48 were canceled after households dropped out of the sample, 11 were canceled because of slip vacancy, and 52 could not be completed because the calls were scheduled before the respective marinas were opened in the spring.

\section{Results}

More than 1.5 million people participated in over 400,000 trips to marinas in the UMRS during the study period. The majority of the use occurred during the summer (79 percent), followed by fall (14 percent), and spring ( 7 percent). Winter use was not measured for the marina slips; most respondents reported not using their marina slips at all during the winter. A breakdown of marina use by season is shown in Figure 18, along with a summary of the related trip and visitor counts that have been estimated.

Recreational boating was the dominant activity of marina slip users. Boating for pleasure was an activity for 94 percent of the participants. All other activities were undertaken by fewer than 10 percent of the visitors. picnicking, waterskiing, and boat fishing were 
the most common activities (all near 5-percent participation). Swimming, camping, and miscellaneous activities (mostly related to boat and slip maintenance) also accounted for small percentages of the overall activities.

Annual estimates for the number of trips, visitors, and recreational activities engaged in during trips are displayed in Table 6. Activities in the table are listed in descending order of participation. For the marina slip survey, the UCL and LCL have been computed at the level of 95-percent confidence.
Figures $19 \mathrm{a}$ and $\mathrm{b}$ illustrate the breakdown of activities engaged in during the study period. Sections of the pie chart represent the proportion of a given activity in comparison with the total of all activities participated in. Activities with small percentages have been combined and identified as "other." Miscellaneous activities that were identified by respondents have also been included in an aggregated category.

\section{Table 5}

Marina User Sample Sizes and Response Rates (UMRS Study, 1990-91)

\begin{tabular}{|c|c|c|}
\hline A. & Number of households & 150 \\
\hline B. & Number of calls/household & $9(1)$ \\
\hline C. & Total possible contacts $(A . \times$ B.) & 1,350 \\
\hline D. & Actual number of completed contacts & 1,082 \\
\hline E. & Number of recreational trips the previous week & 331 \\
\hline F. & Percent of "hits" (E./D.) & $30 \%(2)$ \\
\hline G. & Number mailback questionnaires received & $748(3)$ \\
\hline $\mathrm{H}$. & $\begin{array}{l}\text { Number mailback questionnaires reporting a } \\
\text { recreation trip the previous week }\end{array}$ & 395 \\
\hline I. & Mailback response rate (H./E.) & $119 \%(4)$ \\
\hline $\begin{array}{l}\text { Notes: } \\
1 . \\
2 . \\
3 . \\
\end{array}$ & \multicolumn{2}{|c|}{$\begin{array}{l}\text { Three calls each in spring, summer, fall. } \\
\text { Percent of contacts for which there was a recreational trip the previous week. } \\
\text { Exceeds number of recreational trips the previous week (part E.) because, partway through the study, households } \\
\text { were asked to return their mailback expenditure questionnaires even if they incurred no recreational trips the } \\
\text { previous week. } \\
\text { Exceeds } 100 \% \text { because part } H \text {. exceeds part E. There are two likely explanations. First, many could not be con- } \\
\text { tacted by phone. Since they were sent mailback questionnaires prior to the attempted contacts (part D.), a number } \\
\text { of those who could not be contacted returned their questionnaires anyway. Secondly, there were } 28 \text { telephone } \\
\text { contacts for whom no trips were reported but who returned a mailback questionnaire containing trip expenditures } \\
\text { for the previous week. }\end{array}$} \\
\hline
\end{tabular}




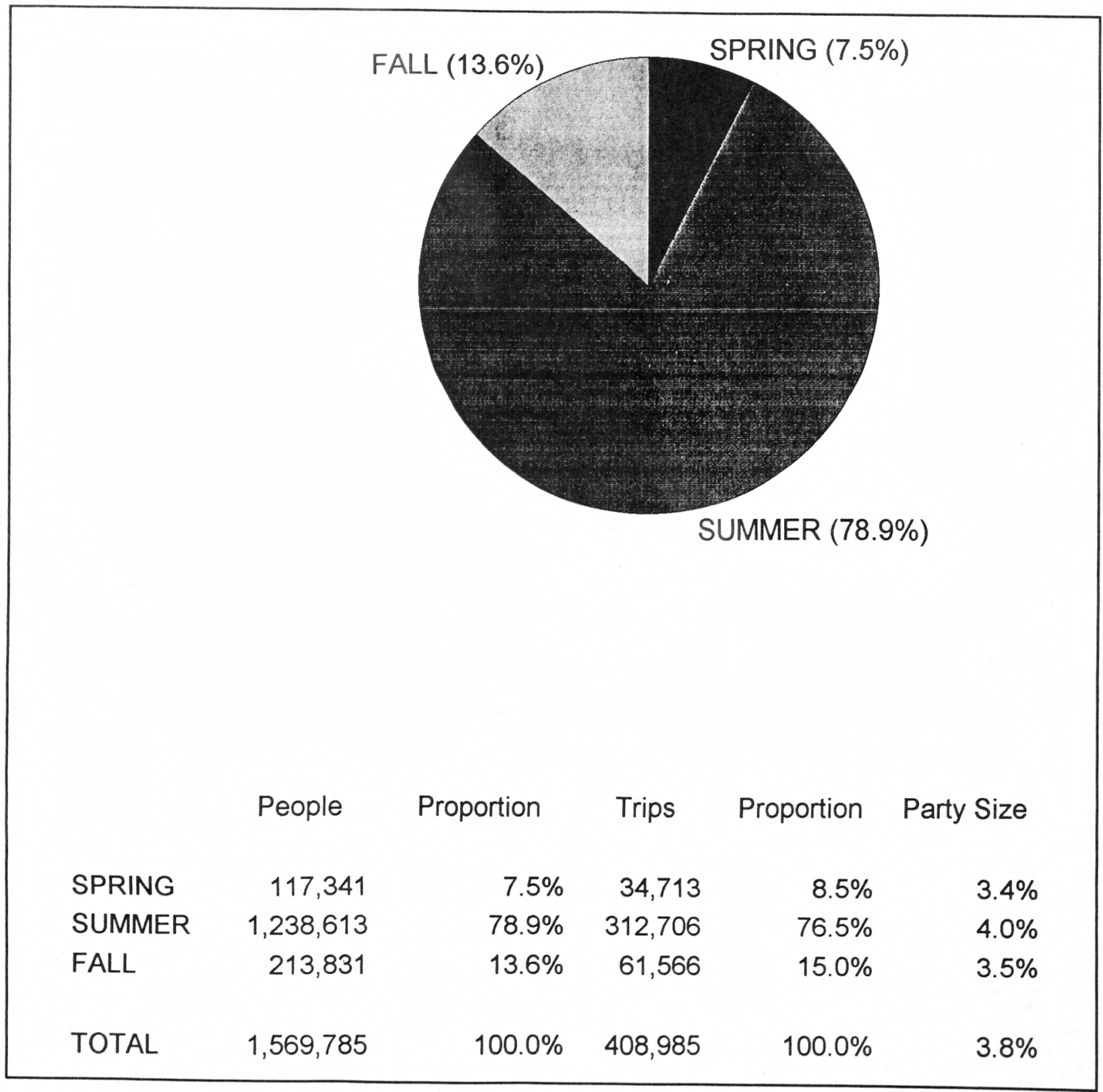

Figure 18. Recreational use of marina slips by season (people) 


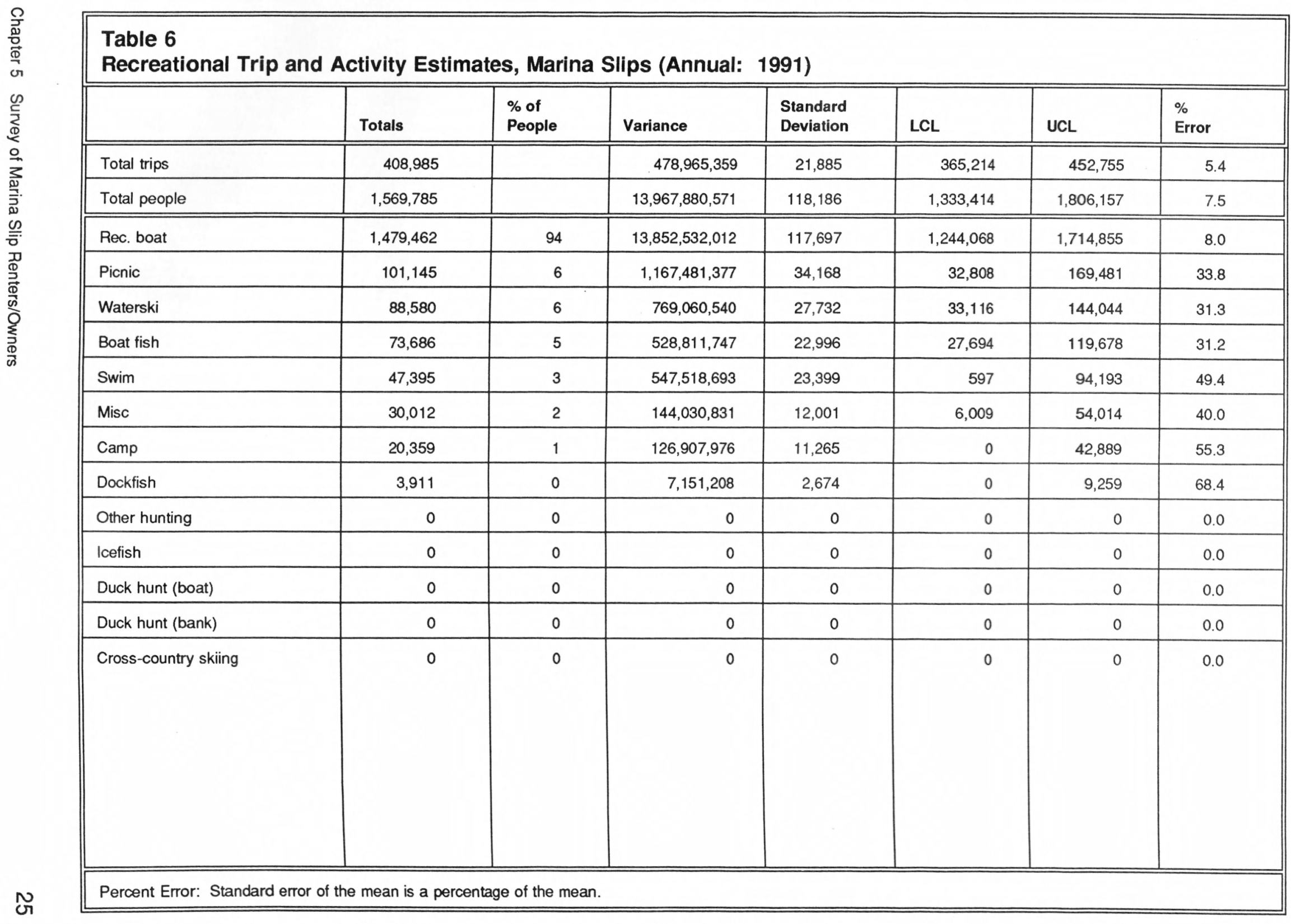




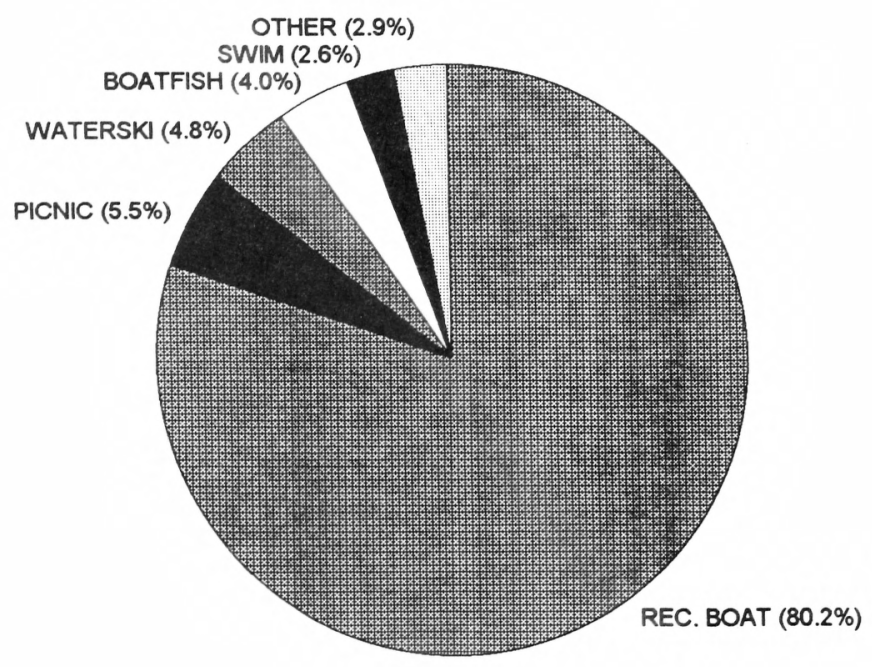

a. Activities breakdown

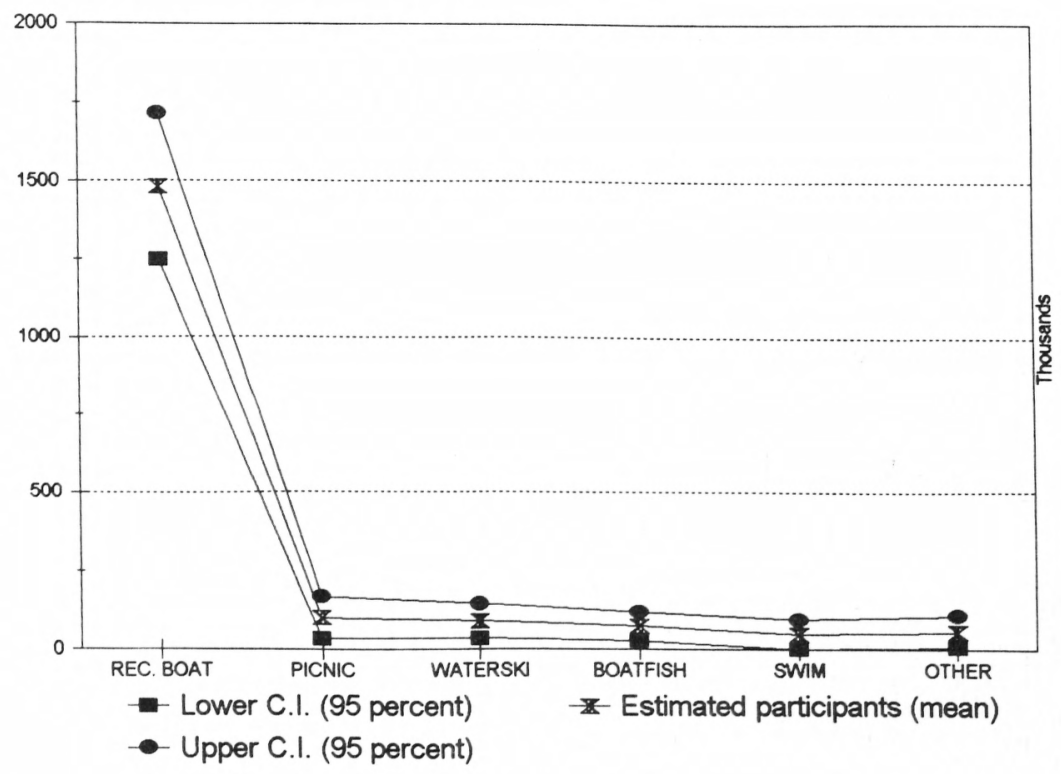

b. Activity estimates and confidence intervals

Figure 19. Marina slips (annual total, 1991) 


\section{Expenditure Survey and Economic Impact Results}

\section{Trip Expenditures}

Expenditures made for recreational purposes cover a wide variety of goods and services. The type of expenditure data collected and the way in which it is analyzed depend on the purpose to which it will be put. Based on discussions with TRT members, it was assumed that the UMRS expenditure data would be used for two primary purposes: (a) as an estimate of total resident and nonresident river-related recreation expenditures and (b) as a basis for driving regional and interregional input/output (I/O) models to estimate economic impacts.

With this in mind, the decision was made to collect two types of spending data:

a. Trip expenditures, or one-time expenses for items that are consumed during the trip, such as gas and food.

$b$. Durable goods expenditures, expenditures for items that last beyond the trip, such as boats and recreational vehicles.

Durable goods expenditures cannot be tied as directly to the recreational trip as trip expenditures, but they do represent, to a certain extent, spending that is induced or enhanced by the availability of the recreational resource.

To use I/O models, it is necessary to add another dimension to the collection of expen- diture data: assignment of spending to specific geographic regions. Ordinarily, these regions would be defined by the study purpose. However, since the TRT members expressed interest in using the data to address a variety of different issues, an attempt was made to define regions that would be applicable to as wide a range of problems as possible without putting too much of a burden on the respondent. Three regions were selected for the study:

a. Counties immediately adjacent to the survey site, homeowner's marina slip, or permitted boat dock (defined in the questionnaire as the area within 30 miles of the survey site, an approximation of the average county size).

$b$. Counties bordering the five rivers in the study area (defined as the area within 30 miles of these rivers).

c. Area outside of the counties included in region 2 (the area outside of the 30-mile border).

\section{Recreation expenditure sampling plan methods}

Visitor contacts made for the use estimation part of the study were used as the mechanism for collecting both the trip and durable goods expenditures, but the analysis procedures for the trip expenditure data were different. Spending profiles were developed for predefined 
user segments rather than for the area/date strata. Eightecn user scgments were created to represent groups that are believed to be relatively homogeneous in terms of type and amount of expenditures. These are presented in Table 7.

The trip expenditure and durable goods expenditure data were collected with separate survey instruments. This was done for two reasons. First, it helps to ensure that survey respondents understand exactly what information is required from them. For a number of reasons, it was essential that the respondent be able to separate the two types of expenditures. In addition, since the trip and durable goods expenditures have different sampling requirements, the separate forms will allow for the most efficient allocation of effort.

\section{Expenditure data collectlon In connection with on-site surveys}

For the surveys at developed recreational areas and sightseeing areas/visitor centers, questions relating to durable goods expenditures were added to the on-site questionnaire for the respondent in a personal interview. At the end of the interview, the respondent was handed a mailback questionnaire containing questions about trip expenditures. This questionnaire was to be completed by the

\begin{tabular}{|c|c|c|c|c|}
\hline \multicolumn{5}{|c|}{$\begin{array}{l}\text { Table } 7 \\
\text { User Segments for Trip Expenditure Profiles }\end{array}$} \\
\hline Segment Number & Day/Overnlght Use & Boater & $\begin{array}{l}\text { Resldent of } \\
\text { UMRS }\end{array}$ & Type of Lodging \\
\hline 1 & day & yes & yes & \\
\hline 2 & day & yes & no & \\
\hline 3 & overnight & yes & yes & campground \\
\hline 4 & overnight & yes & yes & rented accommodations \\
\hline 5 & overnight & yes & yes & friends/relatives/2nd home \\
\hline 6 & overnight & yes & yes & boat \\
\hline 7 & overnight & yes & no & campground \\
\hline 8 & overnight & yes & no & rented accommodations \\
\hline 9 & overnight & yes & no & friends/relatives/2nd home \\
\hline 10 & overnight & yes & no & boat \\
\hline 11 & day & no & yes & \\
\hline 12 & day & no & no & \\
\hline 13 & overnight & no & yes & campground \\
\hline 14 & overnight & no & yes & rented accommodations \\
\hline 15 & overnight & no & yes & friends/relatives/2nd home \\
\hline 16 & overnight & no & no & campground \\
\hline 17 & overnight & no & no & rented accommodations \\
\hline 18 & overnight & no & no & friends/relatives/2nd home \\
\hline
\end{tabular}


respondent once he or she completed the trip, then mailed to the address given.

If the mailback questionnaire was not received within 2 weeks of the respondent's expected home arrival date, a postcard was sent to remind the respondent to complete and return the questionnaire. If after another 2 weeks the questionnaire still was not returned, the respondent was sent by certified mail a second mailback questionnaire. Respondents who did not return the questionnaire after this mailing were considered nonrespondents for data analysis purposes.

\section{Expenditure data collection in connection with telephone surveys}

The procedures for collecting trip and durable goods spending information from marina slip renters and boat dock permit holders were identical, the only difference being the type of recreation-related spending that was measured. Marina slip renters were asked about spending associated with use of their marina slip, while boat dock permit holders were asked about spending associated with use of their boat dock and the land around it.

To minimize costs of the household and marina surveys, the procedures for collecting expenditure data were tied into those for estimating use. During the first telephone contact, the homeowner was asked for information on durable goods that are used in conjunction with recreational traveling, as defined above. If, during the follow-up calls that occurred throughout the year, any member or guest of the household engaged in recreational activities as defined, a trip expenditure questionnaire was mailed to the homeowner. This was completed by the homeowner and returned. The same procedures used in the on-site survey for mailing a postcard reminder and second mailback questionnaire were followed for this group.

\section{Results}

Spending patterns differ among different types of visitors, as well as among types of areas visited. The total annual trip expenditures made in the UMRS, broken down by river access type, are shown on Figure 20. Although trips to developed areas were the most common in the UMRS, they accounted for the lowest average spending per trip (\$69). Trips to marinas had the highest spending average (\$132), followed by trips to permitted docks (\$86) and trips documented at sightsecing/ visitor center areas (\$83). On average, threefourths of the spending took place within 30 miles of the recreational site visited.

Factors that account for differences in spending patterns include trip length, party size, mix of goods purchased, and visitor segments represented. Some of these differences for spending on trips by visitors to developed areas are highlighted in Figures 21 through 25. They have been derived by combining the recreational use and expenditure results from the developed area survey.

Figure 21 displays the total segment shares (percentages) for trips to developed sites $(\mathrm{R}=$ resident, $\mathrm{D}=$ Day user, $\mathrm{B}=$ Boater, $\mathrm{NR}=$ Nonresident, $\mathrm{O}=$ Overnight, $\mathrm{NB}=$ Nonboater). Resident day users were by far the most common visitors, with nonboaters slightly outnumbering boaters.

Total average trip spending for each of the segments is displayed in Figure 22. Spending is presented for the amount spent within 30 miles of the site as well as for total spending on the trip. Overnight visitors spend the most per trip, with residents spending slightly more per trip than nonresidents. Visitors who do not boat spend the least on average.

Figure 23 incorporates the average segment spending from Figure 22 and the total number of trips within each segment to tally total 


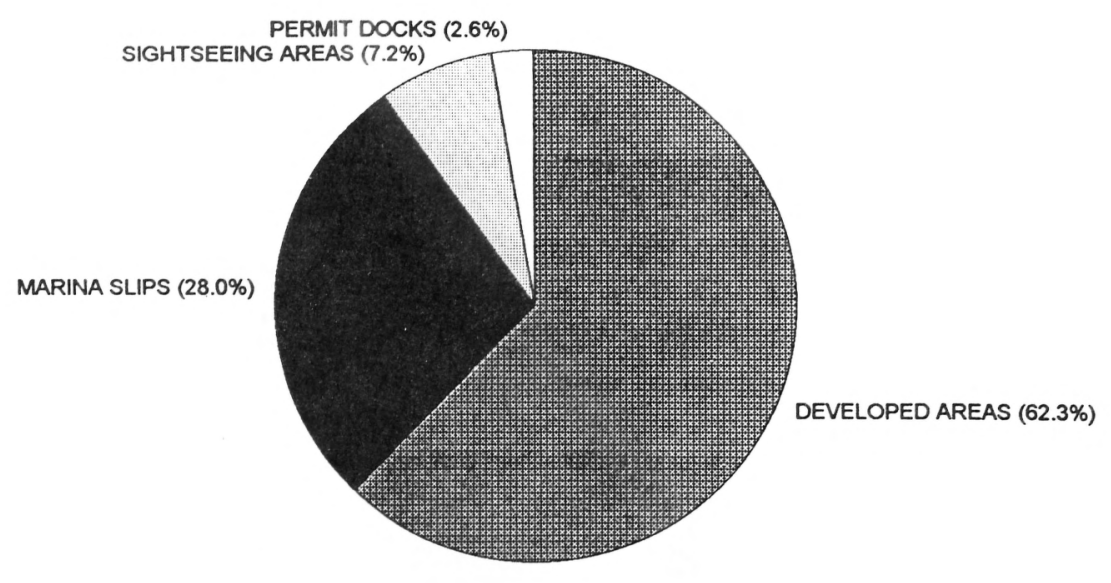

DEVELOPED AREAS

MARINA SLIPS

SIGHTSEEING AREAS

Trips

Spending

Total

(Annual)

$1,732,571$

Per Trip*

Spending *

$\$ 69.05$

$\$ 119,634,028$

408,985

$\$ 131.55$

$\$ 82.95$

$\$ 53,801,977$

$\$ 13,798,069$

57,151

$\$ 85.97$

$\$ 4, Q 13,271$

$\%$ Spent

w/i 30 miles

$69.2 \%$

$85.0 \%$

$65.2 \%$

PERMITTED DOCKS

TOTAL

$2,365,049$

$\$ 81.24 \quad \$ 192,147,345$

$83.1 \%$

$73.6 \%$

DEVELOPED AREAS

MARINA SLIPS

SIGHTSEEING AREAS

PERMITTED DOCKS

TOTAL $\quad 12,126,733$

\section{Spending}

Visitor Days (Annual)

$8,216,174$

$2,637,239$

913,831

359,489

Per

Visitor Day*
Total

Spending*

$\$ 14.56$

$\$ 20.40$

$\$ 15.10$

$\$ 13.67$

$\$ 119,634,028$
$\$ 53,801,977$
$\$ 13,798,069$
$\$ 4,913,271$

$\%$ Spent

w/i 30 miles

$\$ 15.84 \$ 192,147,345$

$69.2 \%$

$85.0 \%$

$65.2 \%$

$83.1 \%$

$73.6 \%$

* 1990 Price Levels

Figure 20. Total expenditures on UMRS trips, by access type 


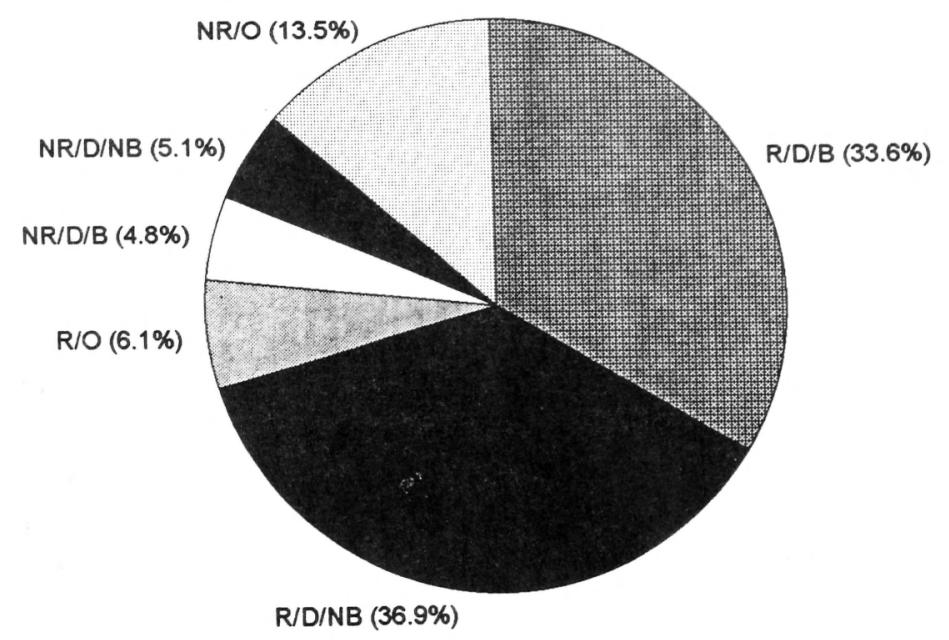

Figure 21. Expenditure segment shares, UMRS developed sites

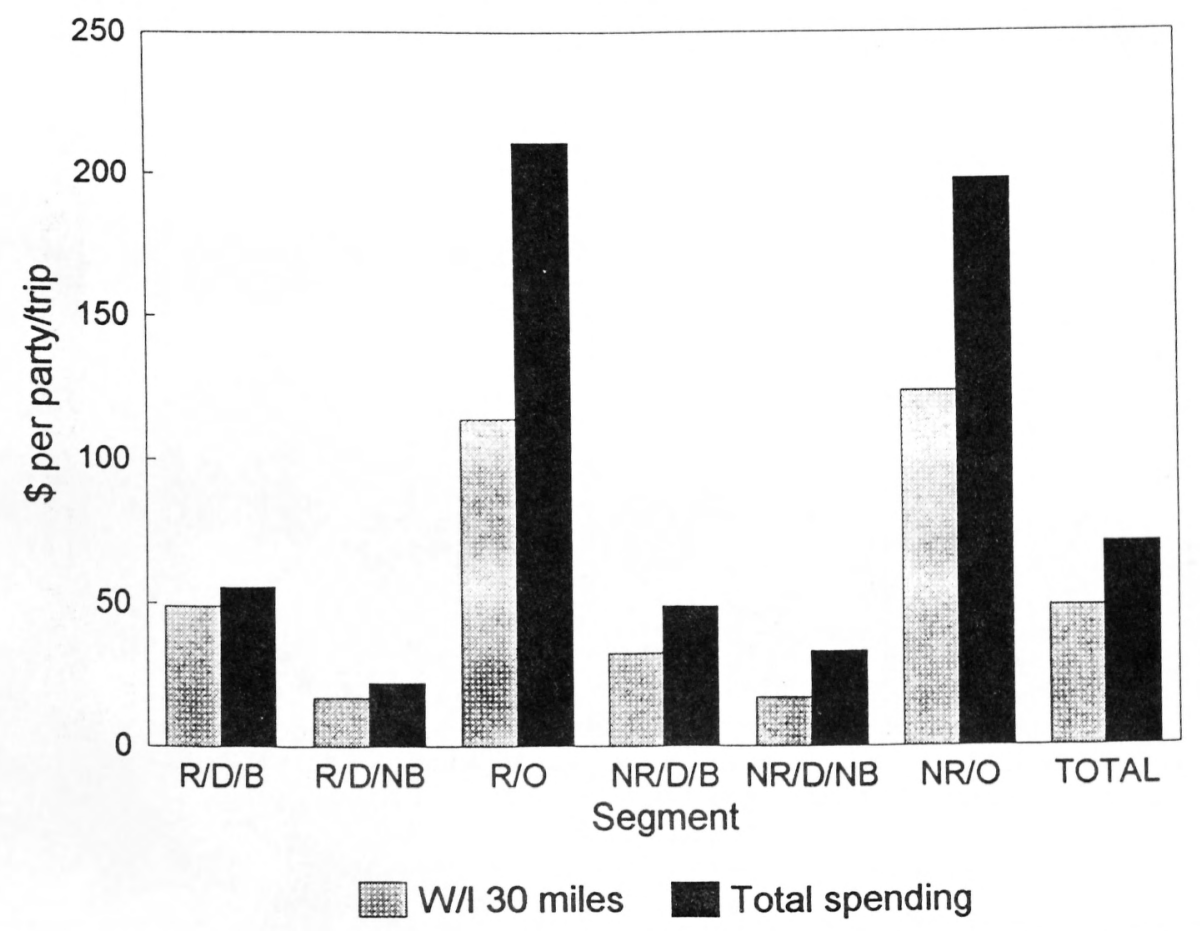

Figure 22. Average trip spending per party/trip by segment, UMRS developed sites 


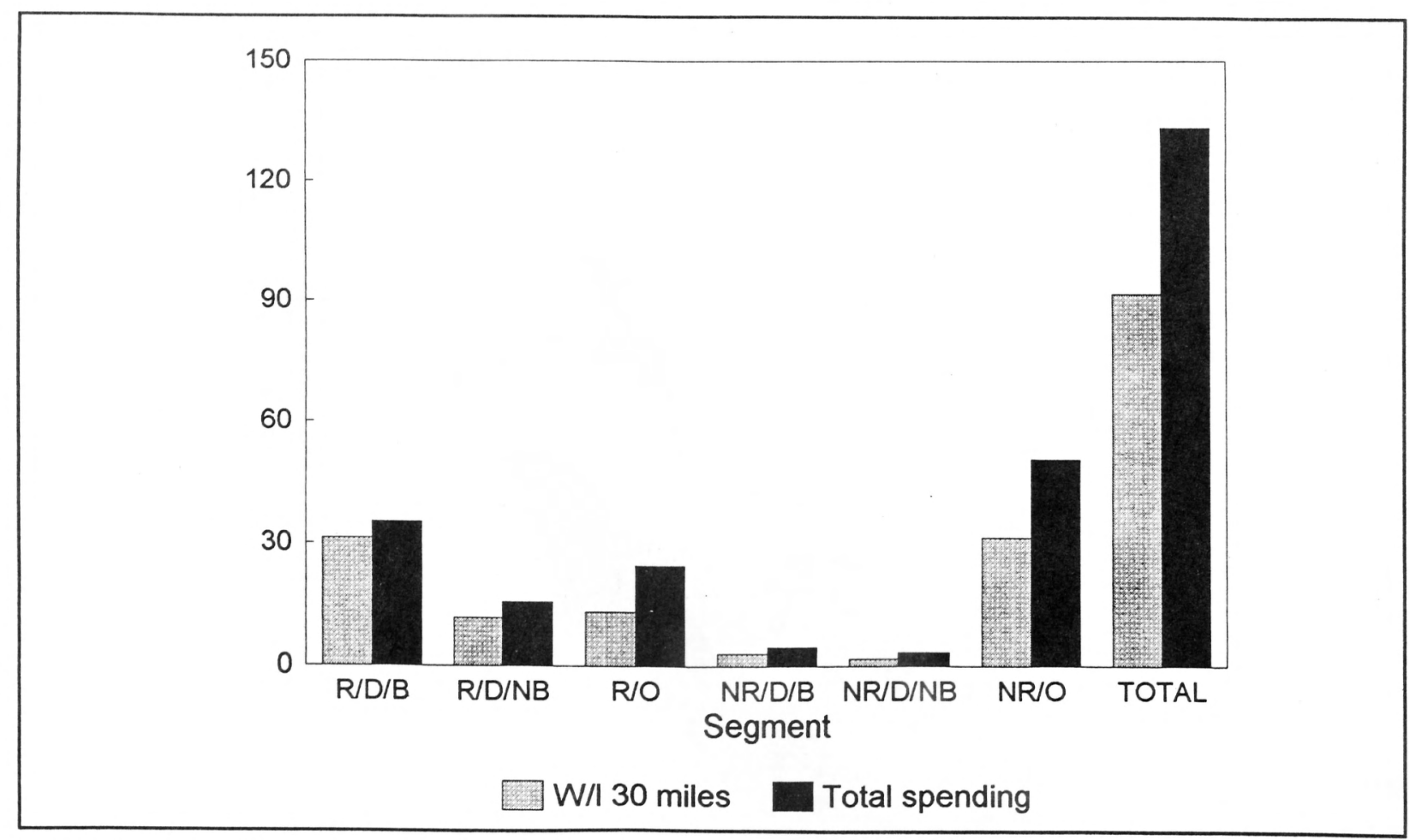

Figure 23. Total trip spending (\$MM) by segment, URMS developed sites

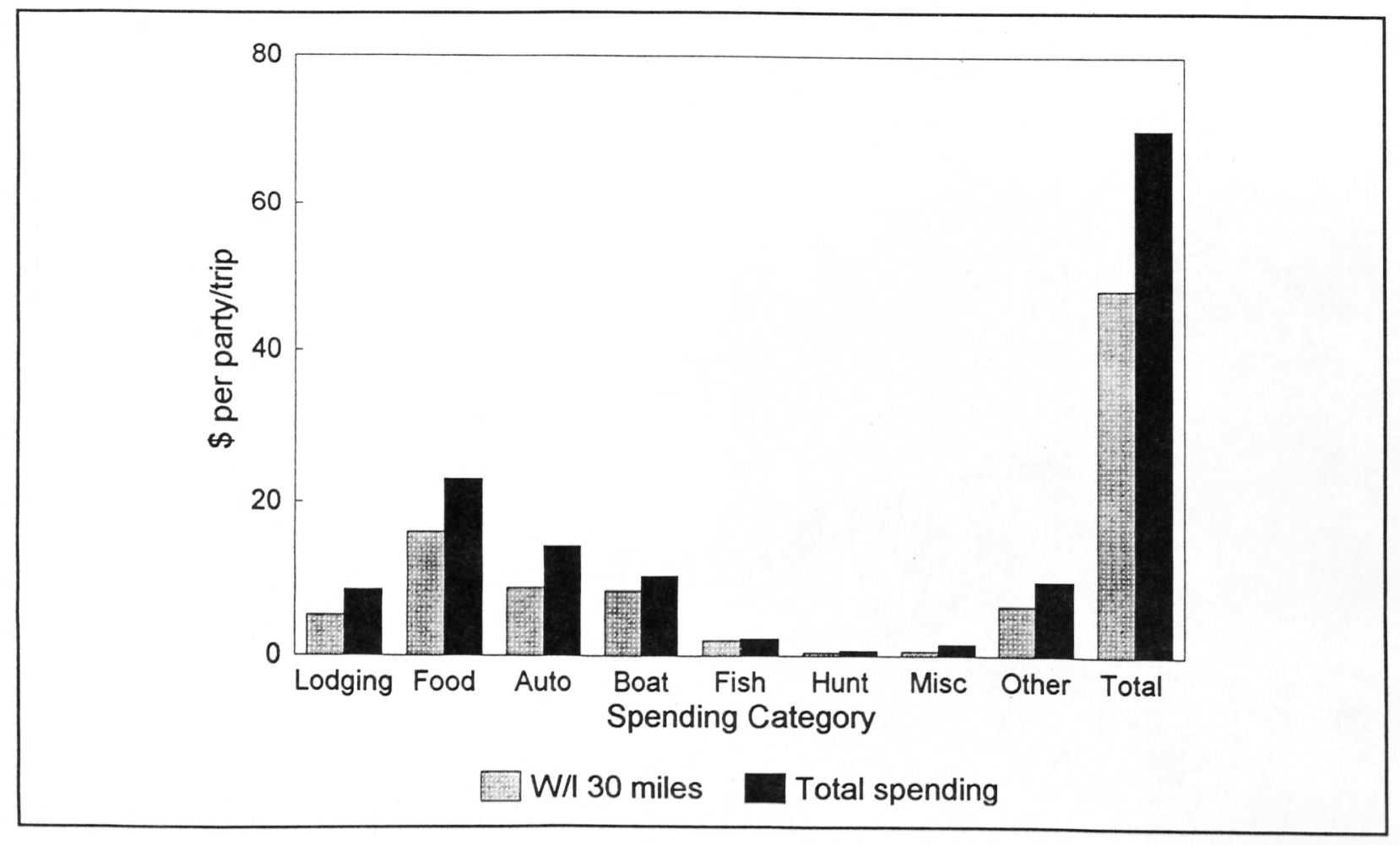

Figure 24. Average trip spending per party/trip by spending category, UMRS developed sites 


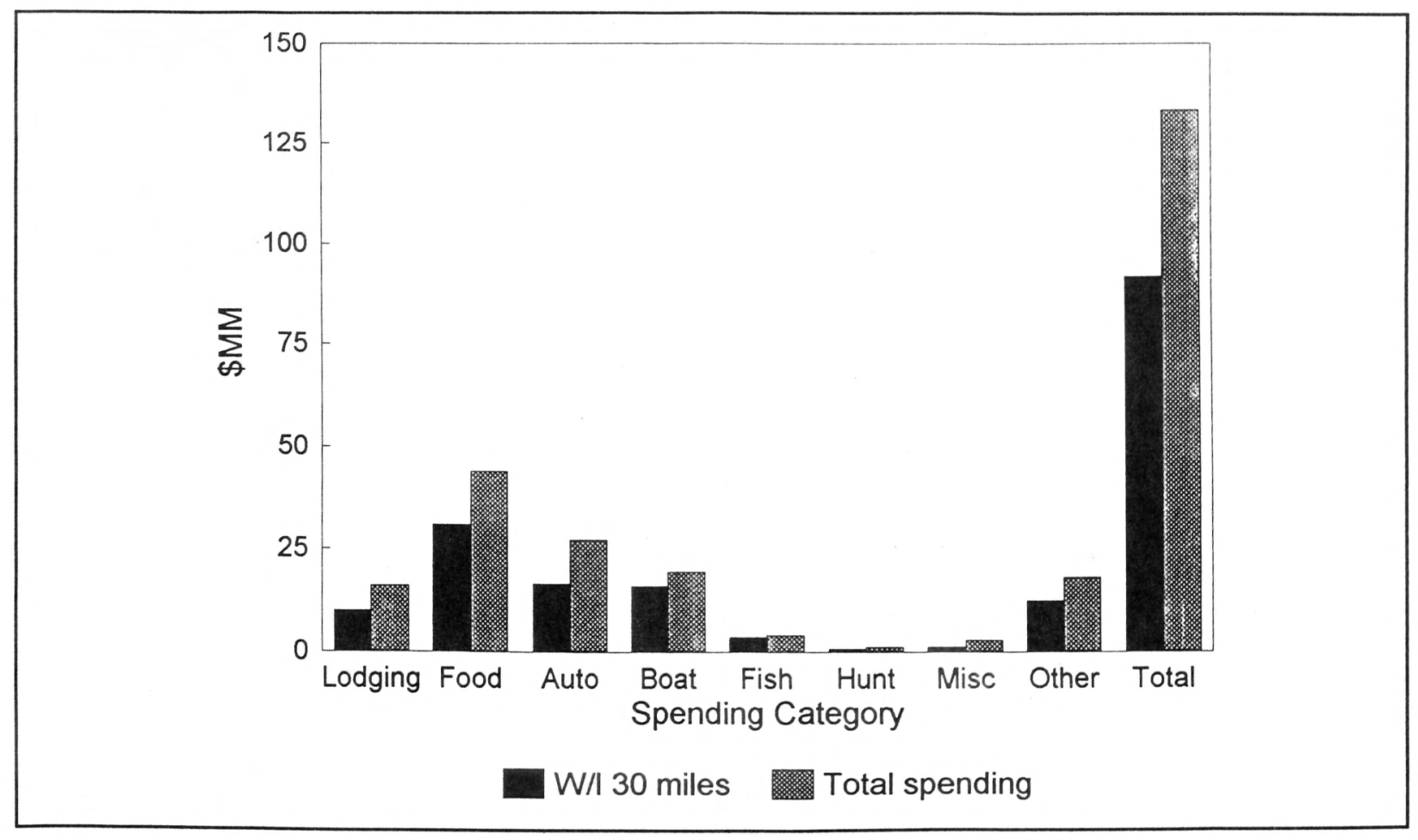

Figure 25. Total trip spending (\$MM), by spending category, UMRS developed sites

spending by segment. Nonresident overnight visitors account for the largest amount of revenue, followed closely by residents in all three categories (R/D/B, R/O, and R/D/NB).

Figure 24 highlights the types of goods and services that are purchased, on average, per trip. Food, automotive, boat, and lodging expenses are the highest. Total expenditures, by spending category, are displayed on Figure 25.

\section{Spending on Durable Goods}

Spending on durable goods used on the trips to the UMRS was also measured in the survey, and is summarized on Figure 26. The purchases have been adjusted to a per-trip average. Durable goods spending per trip was greatest for trips to marina slips ( $\$ 135)$, followed by sightseeing areas (\$54), developed areas (\$50), and permitted docks (\$29). Overall spending on durable goods was largest from trips to developed areas since these areas had the greatest number of trips.
Unlike trip spending, however, durable goods spending cannot be as directly attributed to use of the UMRS. Many durable goods, such as boats, trailers, and camping equipment, can be used for trips outside the UMRS. There has been no attempt in the survey to isolate which durable goods purchases were made specifically for recreation on the UMRS, since procedures to do this are confusing to respondents and likely would have yielded unreliable results in a study of this scope. These purchases, therefore, can only be viewed as "associated with" recreation on the UMRS.

To address this allocation issue in the regional economic analyses, the location of purchase and type of access visited were used as the distinguishing factors. Since durable goods used on trips to developed areas and sightseeing areas are highly mobile, only goods purchased in the UMRS corridor counties have been considered to be directly associated with recreation on the UMRS. This accounts for roughly one-half of the amount of durable goods purchases used on these visits. Durable 


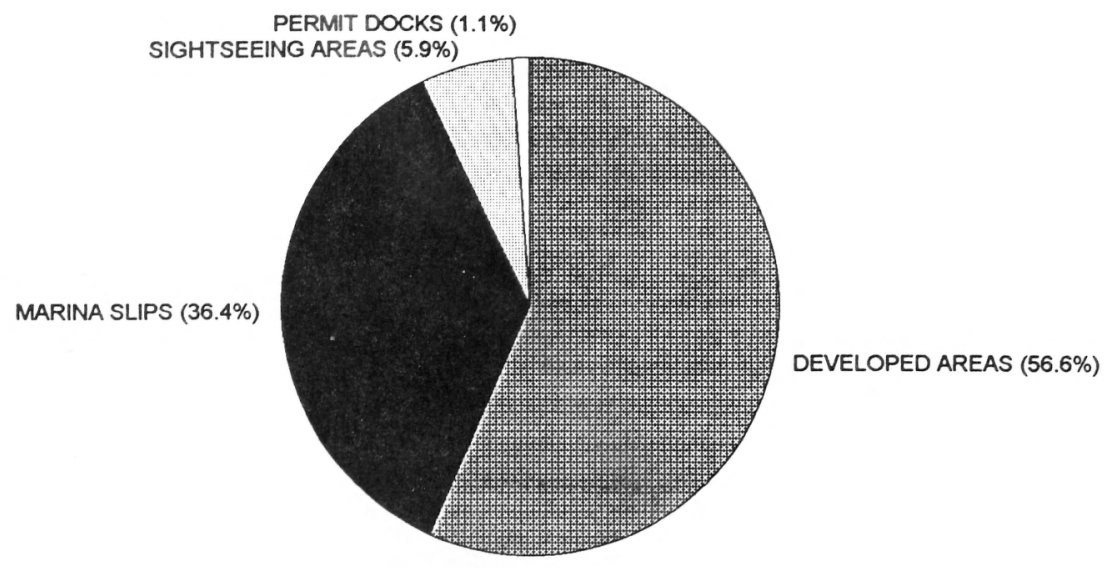

DEVELOPED AREAS

MARINA SLIPS

SIGHTSEEING AREAS

PERMITTED DOCKS

TOTAL $\quad 2,365,049$
(Annual)

$1,732,571$

408,985

166,342

57,151
DEVELOPED AREAS

MARINA SLIPS

SIGHTSEEING AREAS PERMITTED DOCKS

Visitor Days
(Annual)
$8,216,174$
$2,637,239$
913,831
359,489

Spending

Per

Visitor Day*

$\$ 10.48$

$\$ 9.89$

$\$ 4.65$

\begin{tabular}{|} 
Spending \\
Per Trip* \\
49.69 \\
135.26 \\
54.33 \\
29.24
\end{tabular}

$81.24 \$ 152,119,220$

$\$ 20.98$

Total
Spending
$\$ 86,091,453$
$\$ 55,319,311$
$\$ 9,037,361$
$\$ 1,671,095$

$$
\text { Total }
$$

Spending*

$\$ 86,091,453$

$\$ 55,319,311$

$\$ 9,037,361$

$\$ 1,671,095$

$\$ 12.54 \$ 152,119,220$
$\%$ Spent

w/i 30 miles

$49.9 \%$

$34.9 \%$

$35.8 \%$

$75.2 \%$

$43.9 \%$

$\%$ Spent w/i 30 miles

$49.9 \%$

$34.9 \%$

$35.8 \%$

$75.2 \%$

TOTAL $12,126,733$

*1990 Price Levels

Figure 26. Durable goods expenditures related to UMRS trips, by access type 
goods purchases for trips to marinas and permitted docks are more directly tied to recreation on the UMRS. Purchases of durable goods used at these sites (nearly all purchases were made in the five-state region) have been considered directly associated with UMRS recreation and have been included in the fivestate regional analysis and national analysis presented in the next section.

Considering the results of durable goods purchases has the greatest usefulness in studying economic impacts of a large region, such as the UMRS corridor counties or the five states in the study area. Regions of this size are large enough to have some production capacity. Attempting to measure the economic impacts of durable goods purchases on individual projects or small counties has limited usefulness, however, and is generally not recommended. In small or isolated regions, the local effects of durable goods purchases are virtually zero in most circumstances.

\section{Economic Impact Analysis and IMPLAN}

The economic impact analysis completed for this study involves the translation of visitor spending into economic effects in terms of income and employment. This analysis has been accomplished through the use of an I-O model. An I-O model is an accounting system showing economic transactions between local businesses, households, and governments, as well as transactions between public and private entities located elsewhere. An I-O model provides only a static view of economic conditions but can be an effective device for characterizing and analyzing complex local, regional, and national economies. I-O models are constructed for specific geographic regions to capture the specific economic sectors and linkages that exist in the region.
IMPLAN, an I-O model developed by the U.S. Forest Service, was selected for use in this study after considering a number of alternatives. IMPLAN was first developed in 1979, and the current version for microcomputer, Version $91-09,{ }^{1}$ was used in the analyses in this report. A major consideration for selecting IMPLAN was that it provides more detailed information than most other standardized I-O models for recreation-related economic sectors. IMPLAN also allows for flexibility in defining the study area (using any combination of counties in the United States), making it useful for applications beyond the scope of this study. Additionally, IMPLAN allows flexibility in the use of local and regional purchasing coefficients (LPC's and RPC's) that reflect the consumption and production relationships within given regions. Careful consideration of these relationships can lead to more realistic results in regional analyses. User training and support for IMPLAN is also available, which was a consideration in evaluating its usefulness in future applications.

The types of economic effects and regional analyses used in this analysis are described in the following sections.

\section{Economic Effects}

The economic effects of recreational use on the UMRS can be viewed as the income and employment businesses derive as a direct or indirect result of spending by visitors. The total economic effect can be described as the sum of the direct, indirect, and induced effects resulting from recreation-related purchases in an economy. These three distinct types of effects are measured separately by IMPLAN and are reported separately in the analysis.

Direct effects include income and employment resulting from direct spending by visitors

1 University of Minnesota, 1992, "Micro IMPLAN: Microcomputer-based system for economic analysis of states, regions, and communites," St. Paul, MN. 
used on goods and services to engage in recreational activities; for instance, the retail purchase of a boat.

Indirect effects measure the secondary purchases, or "recirculation" of dollars among related firms, resulting from the initial purchase. Continuing the boat example, boating manufacturers will purchase materials and labor to meet the increased demand for boats resulting from increased retail sales; shipping companies will purchase labor, trucks, gasoline, and other supplies; and boat dealers will purchase labor and supplies in support of their retail sales activities.

Induced effects measure the additional "recirculation" of dollars caused by increased employee income generated by the direct and indirect effects of a retail purchase. These increases in employee income lead to more retail purchases in the economy, which lead to further "recirculation" of the original retail dollars expended.

\section{Regional Analysis}

An economic region must be defined to determine the economic effects of an activity. In IMPLAN, a region can include any collection of counties in the United States.

Two basic regions have been used in this analysis: the 76 "border" counties that define the UMRS corridor (plus the city of St. Louis), and the five states that encompass the study area. Additionally, in determining the effects of recreational use at developed sites, four subregions of the UMRS corridor counties were separately analyzed. These regions conform to the boundaries of the U.S. Army Engineer Districts, St. Paul, Rock Island, and St. Louis on the main stem Mississippi River, plus the counties along the length of the Illinois Waterway (excluding the Chicago area). Maps of the regions are included as Appendix A. Since the Corps' district boundaries do not fol- low county boundaries, some counties appear in two adjacent regions.

Each of the regions has a unique set of economic attributes, and each would therefore be affected differently by recreational spending. In general, the larger and more diverse an economic region is, the greater the resulting economic impact from a given activity. This is because more goods and services can be obtained within the region, thus limiting "leakages" of dollars to producers of goods and services outside the region.

In addition to geographic descriptions of the regions used in this report, population and total dollars of activity in a region are reported as indicators of a region's size. These figures appear in Table 8. The figures are taken from summaries prepared in IMPLAN, and reflect conditions in 1985 , the most recent data currently available in IMPLAN. The number of economic sectors included in each region is also reported and can be viewed as an indicator of a region's economic diversity. There are strong similarities between Regions 1 and 3, as well as between Regions 2 and 4.

For each region studied, two types of analysis were performed: analysis of spending made locally (within 30 miles of the respective sites) by nonresidents of the UMRS counties; and analysis of all spending made locally (residents and nonresidents). The analyses will also distinguish between purchases of items that are consumed during the recreational trips (gas, food, lodging, bait, etc.) and purchases of durable items (boats, fishing gear, clothing, etc.).

\section{Economic effects of spending In the UMRS corrldor countles}

The economic effects of recreation originating from all surveyed populations in the study area are summarized in Table 9 . These figures represent all spending on recreational trips within the border counties that define the study area. This spending was 73.6 percent 


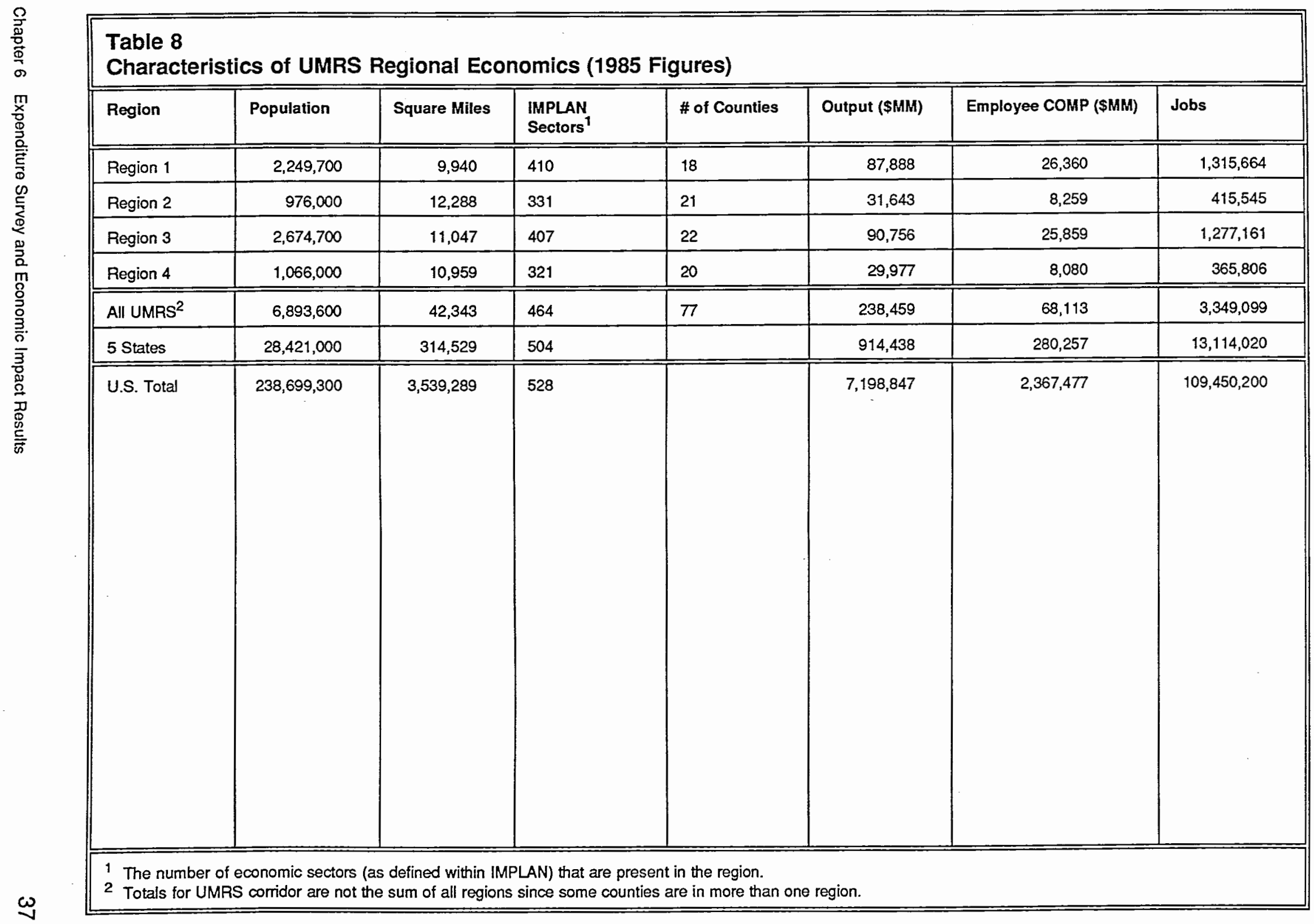




\begin{tabular}{|c|c|c|c|c|c|c|}
\hline \multicolumn{7}{|c|}{$\begin{array}{l}\text { Table } 9 \\
\text { Economic Effects of Recreatlonal Spending UMRS Corrldor: G } \\
\text { are annual, reported at } 1985 \text { price levels) }\end{array}$} \\
\hline & \multirow[b]{2}{*}{ Direct } & \multirow[b]{2}{*}{ Indirect } & \multirow[b]{2}{*}{ Induced } & \multirow[b]{2}{*}{ Total } & \multicolumn{2}{|c|}{ Multipliers } \\
\hline & & & & & Type 1 & Type III \\
\hline \multicolumn{7}{|c|}{ Trip Spending } \\
\hline \multicolumn{7}{|c|}{ Nonresident local spending } \\
\hline Output (\$MM) & 47.34 & 20.20 & 62.32 & 129.86 & 1.43 & 2.74 \\
\hline Income (\$MM) & 13.61 & 5.13 & 17.39 & 363.13 & 1.38 & 2.65 \\
\hline Jobs & 1,089 & 282 & 1,024 & 2,395 & 1.26 & 2.20 \\
\hline \multicolumn{7}{|c|}{ All local spending } \\
\hline Output (\$MM) & 122.44 & 51.40 & 150.89 & 324.73 & 1.42 & 2.65 \\
\hline Income (\$MM) & 34.79 & 13.04 & 42.11 & 89.94 & 1.37 & 2.59 \\
\hline Jobs & 2,595 & 714 & 2,480 & 5,789 & 1.28 & 2.23 \\
\hline \multicolumn{7}{|c|}{ Durable Goods Spending } \\
\hline \multicolumn{7}{|c|}{ Nonresident local spending } \\
\hline Output (\$MM) & 4.52 & 2.03 & 6.01 & 12.56 & 1.45 & 2.78 \\
\hline Income (\$MM) & 1.59 & 0.54 & 1.67 & 3.80 & 1.34 & 2.39 \\
\hline Jobs & 108 & 30 & 99 & 237 & 1.28 & 2.19 \\
\hline \multicolumn{7}{|c|}{ All local spending } \\
\hline Output (\$MM) & 27.27 & 12.18 & 37.74 & 77.19 & 1.45 & 2.83 \\
\hline Income (\$MM) & 9.64 & 3.23 & 10.52 & 23.39 & 1.34 & 2.43 \\
\hline Jobs & 652 & 180 & 619 & 1,451 & 1.28 & 2.23 \\
\hline
\end{tabular}

of all trip spending (Figure 20). Note that all figures in Table 8 and subsequent tables have been deflated to 1985 price levels by IMPLAN for internal consistency in running the model. (The discount from 1990 prices to 1985 prices is approximately 5 percent.)

Table 9 contains separate listings for trip spending and durable goods spending, as well as for nonresident spending within 30 miles and total spending within 30 miles. Three separate measures are reported: total output, total income to employees, and jobs supported by the spending. Three types of economic effects are contained in the matrix: direct spending by visitors, indirect effects, and induced effects. In addition, two types of economic multipliers have been computed. Type I multipliers consider the effect of direct and indirect activity generated by a given amount of spending [(Direct + Indirect)/Direct]. Type III multipliers consider the effect of total activity in relation to a given amount of spending [(Direct + Indirect + Induced $) /$ Direct $]$. Higher multipliers are an indication of greater economic capacity and diversity within a given region.

The results in Table 9 show that direct trip spending in the UMRS corridor counties 
generated a total of $\$ 325$ million in economic activity in the region. About $\$ 90$ million of this amount was wages to employees. A total of 5,789 jobs were supported by this activity. Just over one-third of this activity was due to "new" dollars brought to the region by visitors who permanently live outside the UMRS area. The portions of the economic impacts that are due to the different surveyed populations are similar to the proportions of total expenditures presented on Figure 20.

Spending on durable goods in the UMRS corridor counties generated a total of $\$ 77$ million in economic activity in the region. Over $\$ 23$ million of this amount was wages to employees. A total of 1,451 jobs were supported by purchases of durable goods in the region. Only one-sixth of this activity was due to nonresidents making purchases in the UMRS corridor counties.

This amount of activity accounts for only a very small portion of total economic activity in the region-less than 1 percent. The $\$ 400$ million in trip and durable goods spending compares with total economic output of $\$ 238$ billion in the UMRS corridor counties. Similarly, the 7,000-plus jobs that are supported by recreational purchases compare with nearly 7 million total jobs in the region.

The value of considering economic "importance" for this large a region is rather limited compared to its value in considering importance in relation to specific recreation areas or industries. Recreation expenditures play a more "important" role in specific areas within the basin, but this detail is lost at the level of aggregation required for this study.

\section{Economic effects of spending on the five-state and national economles}

The previous section examined the effects of spending that occurred in the UMRS region only. Virtually all of the remaining spending associated with UMRS recreation was made within the five states of the study area. The effects of total spending on the five-state economy, and on the national economy, are presented in Tables 10 and 11 , respectively. More than $\$ 550$ million in total output and more than 10,000 jobs in the five states in the study area were supported by UMRS recreational spending. Comparable figures for the national economy are $\$ 1.2$ billion in output and over 18,000 jobs.

Figures in these tables represent all spending made on trip related purchases. For durable goods purchases associated with marina slips and permitted docks, all spending is included; for durable goods purchases associated with developed sites and sightseeing areas, only the spending made within the UMRS counties is included. The distinction for developed sites and sightseeing areas is made to attempt to include only those purchases that were made specifically for use on UMRS recreational trips. Durable goods purchases made within the UMRS counties and used at UMRS sites were counted as wholly attributable to UMRS recreational visits for the purposes of this report. 


\section{Table 10}

Economic Effects of Recreational Spending, Five States (MN, WI, IA, IL, MO): Grand Total (All figures are annual, reported at 1985 price levels)

\begin{tabular}{|c|c|c|c|c|c|c|}
\hline & \multirow[b]{2}{*}{ Direct } & \multirow[b]{2}{*}{ Indirect } & \multirow[b]{2}{*}{ Induced } & \multirow[b]{2}{*}{ Total } & \multicolumn{2}{|c|}{ Multipliers } \\
\hline & & & & & Type 1 & Type III \\
\hline \multicolumn{7}{|c|}{ Trip Spending } \\
\hline \multicolumn{7}{|l|}{ All Spending } \\
\hline Output (\$MM) & 155.48 & 70.59 & 219.07 & 445.14 & 1.45 & 2.86 \\
\hline Income (\$MM) & 50.16 & 19.11 & 65.62 & 134.89 & 1.38 & 2.69 \\
\hline Jobs & 3,487 & 968 & 3,587 & 8,042 & 1.28 & 2.31 \\
\hline \multicolumn{7}{|c|}{ Durable Goods Spending } \\
\hline \multicolumn{7}{|c|}{$\begin{array}{l}\text { (Developed \& Sightseeing Areas: Corrldor Spending) } \\
\text { (Dock \& Marina: All Spending) }\end{array}$} \\
\hline Output (\$MM) & 40.09 & 17.86 & 58.92 & 116.87 & 1.45 & 2.92 \\
\hline Income (\$MM) & 15.57 & 5.13 & 17.66 & 38.36 & 1.33 & 2.46 \\
\hline Jobs & 949 & 254 & 965 & 2,168 & 1.27 & 2.28 \\
\hline
\end{tabular}

\section{Table 11}

Economic Effects of Recreational Spending, United States: Grand Total (All figures are annual, reported at 1985 price levels)

\begin{tabular}{|c|c|c|c|c|c|c|}
\hline & \multirow[b]{2}{*}{ Direct } & \multirow[b]{2}{*}{ Indirect } & \multirow[b]{2}{*}{ Induced } & \multirow[b]{2}{*}{ Total } & \multicolumn{2}{|c|}{ Multipliers } \\
\hline & & & & & Type I & Type III \\
\hline \multicolumn{7}{|c|}{ Trip Spending } \\
\hline \multicolumn{7}{|l|}{ All Spending } \\
\hline Output (\$MM) & 181.56 & 148.51 & 523.95 & 854.02 & 1.82 & 4.70 \\
\hline Income (\$MM) & 59.61 & 37.55 & 151.41 & 248.57 & 1.63 & 4.17 \\
\hline Jobs & 3,765 & 1,782 & 7,921 & 13,468 & 1.47 & 3.58 \\
\hline \multicolumn{7}{|c|}{ Durable Goods Spending } \\
\hline \multicolumn{7}{|c|}{$\begin{array}{l}\text { (Developed \& Sightseeing Areas: Corrldor Spending) } \\
\text { (Dock \& Marina: All Spending) }\end{array}$} \\
\hline Output $(\$ M M)$ & 69.43 & 56.61 & 197.71 & 323.75 & 1.82 & 4.66 \\
\hline Income (\$MM) & 25.34 & 16.33 & 57.12 & 98.79 & 1.64 & 3.90 \\
\hline Jobs & 1,378 & 721 & 2,988 & 5,087 & 1.52 & 3.69 \\
\hline
\end{tabular}




\section{Applicability of Results}

\section{Applications}

The study products will cnable managers and planners to conduct economic impact studies at the local level practically and confidently. Such studies have been impractical in the past, because visitor spending patterns, and their relationship to local economies, were not known and were costly to determine.

Reports documenting the study methods and results, and training sessions in study methods and the use of the regional economic model (IMPLAN), have been presented to UMRS planners. Training in the study methods and use of the IMPLAN regional economic model was held in 1992. Over 20 individuals received the training, representing a variety of state and Federal agencies, and universities. These stakeholders and policymakers will use the study products directly in decision-making regarding economic development, river use allocation, and resource protection.

Anticipated applications of study results include justification of new programs or facilities, such as marina expansion or new boat ramps; evaluation of alternative management options, taking into account the balance of river uses and environmental integrity; consideration of cost-sharing approaches; and comparison of economic development options.

The study will also provide a necessary link in assessing overall demand for the UMRS as a resource, and in assessing its economic and environmental carrying capacity. The study results will make it more possible to achicve a comprehensive strategy for managing the UMRS. The study results can be used in combination with natural resource monitoring data and commercial navigation data to evaluate the economic output potential and environmental sustainability of the UMRS as a national resource.

\section{Opinions of Respondents}

The length and complexity of the questionnaires used to collect economic impact information prohibited any detailed inquiries regarding the attitudes and opinions of UMRS recreationists. Respondents were given opportunities to express their opinions about several management issues in the surveys, however.

All participants in the developed areas and sightseeing/visitor center areas survey were asked what they would have done if the UMRS had not been available for recreation on the day of their trip. This question was asked during face-to-face on-site interviews.

Respondents to a mailback expenditure questionnaire were given the opportunity to express their opinions regarding what they perceive to be the major management issues in the UMRS. The questions varied somewhat, since they were tailored to meet the interests of the specific population being surveyed. All of these questions were open ended. Because 
of the design of the marina and permitted dock surveys, respondents in these surveys had the opportunity to state their opinions each time they made a trip within the sampling frame. Responses taken from the marina and permitted dock surveys may, therefore, be weighted toward the opinions of persons who made more recreational trips.

\section{Avallability of the UMRS for recreation}

Participants in the on-site surveys were asked to consider what alternative they would have chosen if the UMRS had not been available for their trip that day. Most parties (70 percent) said they still would have made a recreational trip of some kind. Trips to nonriver sites within the UMRS corridor were the most common alternative preference ( 37 percent), followed by trips to sites outside the UMRS corridor (18 percent) and trips to a combination of sites inside and outside the UMRS corridor (15 percent). The remaining parties felt they would not make a trip (28 percent) or were undecided ( 2 percent). There was little overall difference in preferences expressed between residents of the UMRS and visitors to the region; nonresidents were somewhat more likely than residents to choose sites outside the UMRS corridor as their alternate preference (28 percent and 14 percent, respectively).

\section{Management issues of concern to respondents}

Participants in all three surveys were asked the following question: "What do you believe is the most important issue that affects the management of the Upper Mississippi River Basin?" By far, the most common concerns were related to the environmental quality of the UMRS. Over 40 percent of all respondents identified concerns relating to water quality, pollution and debris, protecting wildlife, and similar concerns. The other most important issues identified, which accounted for nearly another 40 percent, were controlling water levcls, boat traffic concerns (including boat wakes and safety), and maintaining channels through dredging. The remaining responses fall under the following general areas of concern: law enforcement and regulations; shoreline and access improvement; balancing river uses; river stakeholder interaction; maintenance and improvement of facilities; and tax/money issues.

\section{Reason for selecting site}

Respondents to the mailback survey for the developed areas and sightseeing/visitor center areas were asked to identify the main reason they selected the site they were at that day. There were two dominant reasons for choosing sites, each mentioned by approximately 30 percent of the respondents. These reasons were the convenience of the site's location, and the aesthetic appeal of the site. Quality of the fishing or hunting opportunities accounted for another 20 percent of responses. Other reasons for choosing sites included the quality of the buildings, campsites, or other facilities; accessibility of the river through boat ramps; personal referrals recommending the site; and selection due to overcrowding at other sites.

\section{Desired Improvements at developed sites}

Respondents to the mailback survey for the developed areas and sightseeing/visitor center areas were also asked to identify any improvements they would like to see at the site they visited that day. These responses have been summarized across sites in this section to identify the types of improvements most frequently cited. Improvements to buildings and campsites were identified most often (by roughly one-third of respondents), followed closely by improvements to boat docks, ramps, and landings (mentioned by nearly 30 percent of respondents). Improvements to parking, road, and walkway facilities were mentioned by 10 percent of respondents, as were improvements to channel and harbor access. Other responses 
have been categorized as follows: improving water quality and protecting the environment; better maps, information and interpretive services; improved water control/flood control; law enforcement and regulations; and boat traffic and safety.

\section{Problems encountered}

Respondents to the mailback survey for the permitted dock and marina surveys were asked to identify any problems they encountered in association with their trip. The predominant problems identified related to water levels, which account for nearly two-thirds of all responses. Respondents reported water levels that were too high as well as too low. This indicates that the survey took place over a wide geographic area, over a period of nearly 2 years.

Additional problems encountered by boaters included: pollution; condition of facilities; weather; traffic and safety concerns (and conflicts with barges); siltation and weeds; and law enforcement and regulation concerns.

\section{Desired improvements on the UMRS}

Respondents to the marina and permitted dock surveys were also given an opportunity to identify any improvements they would like to see on the UMRS. The most commonly mentioned improvements for both populations (accounting for nearly 60 percent of all responses) related to flood/water control, environmental quality, and channel maintenance. Interest in improved facilities, concerns of traffic and safety, and improvements in regulation and enforcement were also frequently mentioned. A small number of suggestions for specific recreation projects and river projects were also made.

\section{General Limitations of Summary Results}

This section summarizes a number of potential limitations to the study results which primarily relate to sampling, measurement, and modeling issues. Many of these limitations are a result of the large size and complexity of the study area. These issues would be more manageable if similar methods were applied in a smaller study area.

The basin-wide results presented in this section have been combiried from the three scparate surveys conducted between 1989 and 1991. All three surveys produced annual results, but the fact that they are based on separate time periods sampled may have introduced bias into the aggregated results. Conditions such as water level, weather, or the state of the economy during the different periods could have made one sampling season more or less desirable to recreationists than another.

The narrow focus of the study, based on the four populations surveyed, should also be remembered when interpreting the results. Recreation from a number of access types or activities along the river has not been accounted for due to study limitations. These categories include: nondeveloped access sites, river festivals, urban riverfront parks, private hunting clubs, nonpermitted docks, fishing tournaments, commercial boat tours, and gambling boats. The populations that were not surveyed may also be important when considering management alternatives on the UMRS.

The sample sizes for many activities are small and their estimates have large associated variances. This is especially true for data broken down by region. The general magnitude of these figures can be gauged in comparison 
to other figures with some confidence, but making comparisons between these statistics is not recommended, given the accuracy of the data.

Within the realm of the I-O analysis, the large and unusually shaped study area presents problems when considering it as a functional economy. The UMRS corridor contains two large metropolitan areas (St. Louis and the Twin Cities) as well as several midsize economies (e.g., Quad Cities, Peoria). IMPLAN assumes cconomic activity will first take place inside this corridor (length-wise) rather than in surrounding areas that may actually be involved in the activity, too. The corridor's proximity to the Chicago area, for example, may not be well represented in the model. Including Chicago in the model has other complications, however, since it would likely overstate the level of activity in the region. Presenting the impact on the five states and the nation has been done in part to account for these unusual circumstances.

The shape of the study area caused similar difficulty in describing spending inside and outside the region. Trip spending was defined as within or outside 30 miles of the site rather than in the UMRS corridor for two reasons: to avoid confusion in respondents, who were already burdened with regional definition in describing purchases; and to maintain consistency in the survey instrument, since future applications would typically use the 30-mile designation for determining local impacts. The result of this imprecision in measurement is that some trip-related spending by visitors that took place along the corridor more than 30 miles from the site has been misreported as outside the study area. (St. Louis residents who visited a Hannibal river site, for example, may have purchased gas along the way, but more than 30 miles from the Hannibal site.) This measurement problem would have underreported the percentage of trip-spending made in the UMRS counties, but would not affect total spending reported (as in the five-state model, Table 10). This problem did not occur for durable goods spending, because the county of purchase was documented in the survey. 


\section{Bibliography}

Cochran, W. G. (1977). Sampling techniques. 3rd ed., Wiley, New York.

Dillman, D. A. (1978). Mail and telephone surveys - the total design method. Wiley, New York.

Jackson, R. S., Stynes, D. J., Propst, D. B., and Siverts, L. E. (1990). "Economic impact analysis as a tool in recreation program evaluation," U.S. Army Engineer Waterways Experiment Station, Vicksburg, MS.

Ott, L. (1977). An introduction to statistical methods and data analysis. Duxbury Press, North Scituate, MA.

Propst, D. B. (1985). Assessing the economic impacts of recreation and tourism. Southeastern Forest Experiment Station, Asheville, NC.

Scheaffer, R. L., Mendenhall, W., and Ott, L. (1990). Elementary survey sampling. PWS-KENT Publishing Company, Boston, MA.
Stynes, D. J., and Propst, D. B. (1992). “A system for estimating local economic impacts of recreation and tourism, Version 1.0." Department of Park \& Recreation Resources, Michigan State University, East Lansing, MI.

Stynes, D. J., and Propst, D B. (1992). "Micro-Implan Recreation economic impact estimation system Users' Manual," Department of Park \& Recreation Resources, Michigan State University, East Lansing, MI.

Upper Mississippi River Conservation Committee. (1982). "Outdoor recreation: Big business on the UMRS," Rock Island, IL.

U.S. Army Engineer District, St. Paul. (1983). "Upper Mississippi River land use allocation plan," St. Paul, MN.

Walsh, R. G. (1985). "Recreation economic decisions," Colorado State University, Fort Collins, CO. 



\section{Appendix A Study Area Maps}




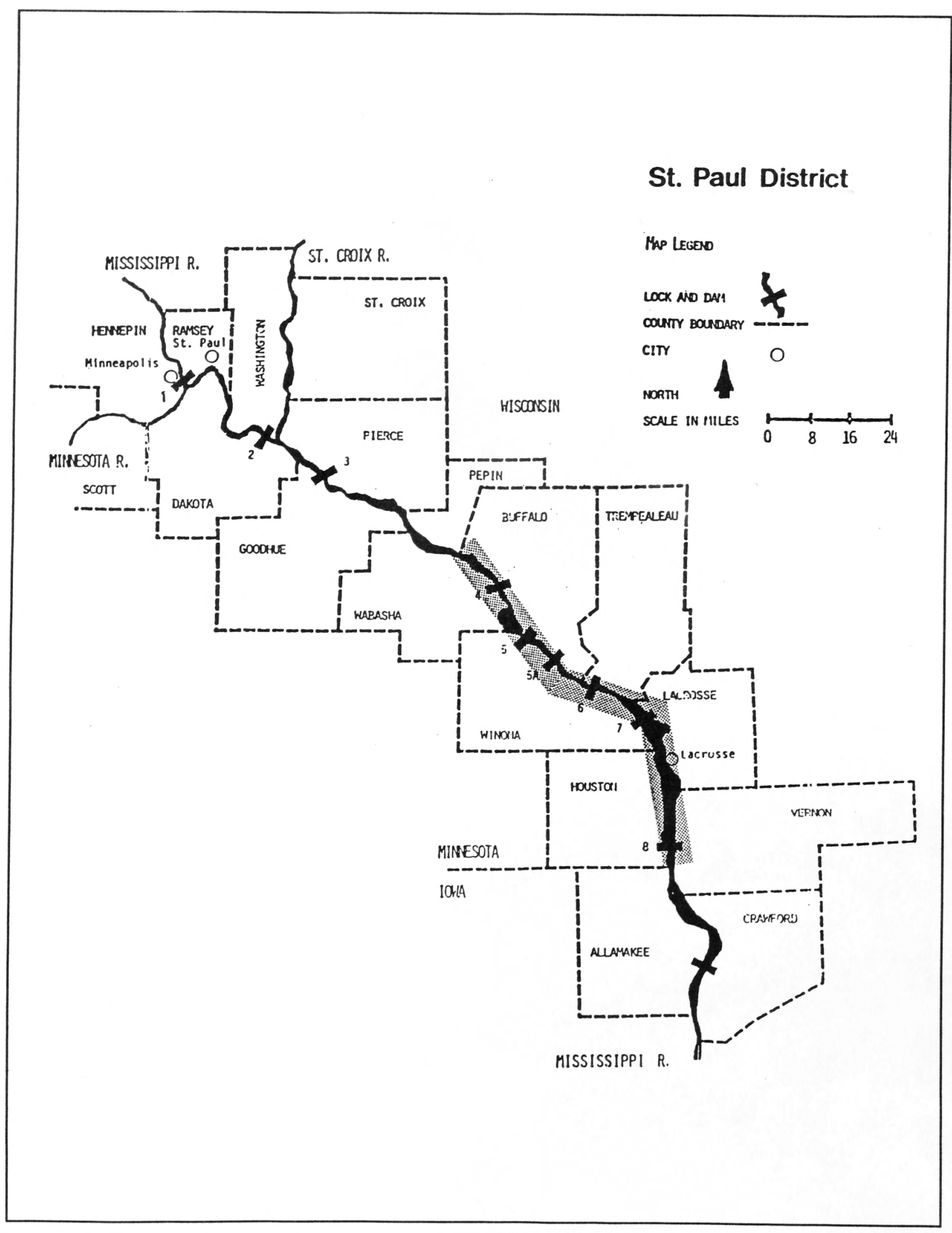

Figure A1. St. Paul District 


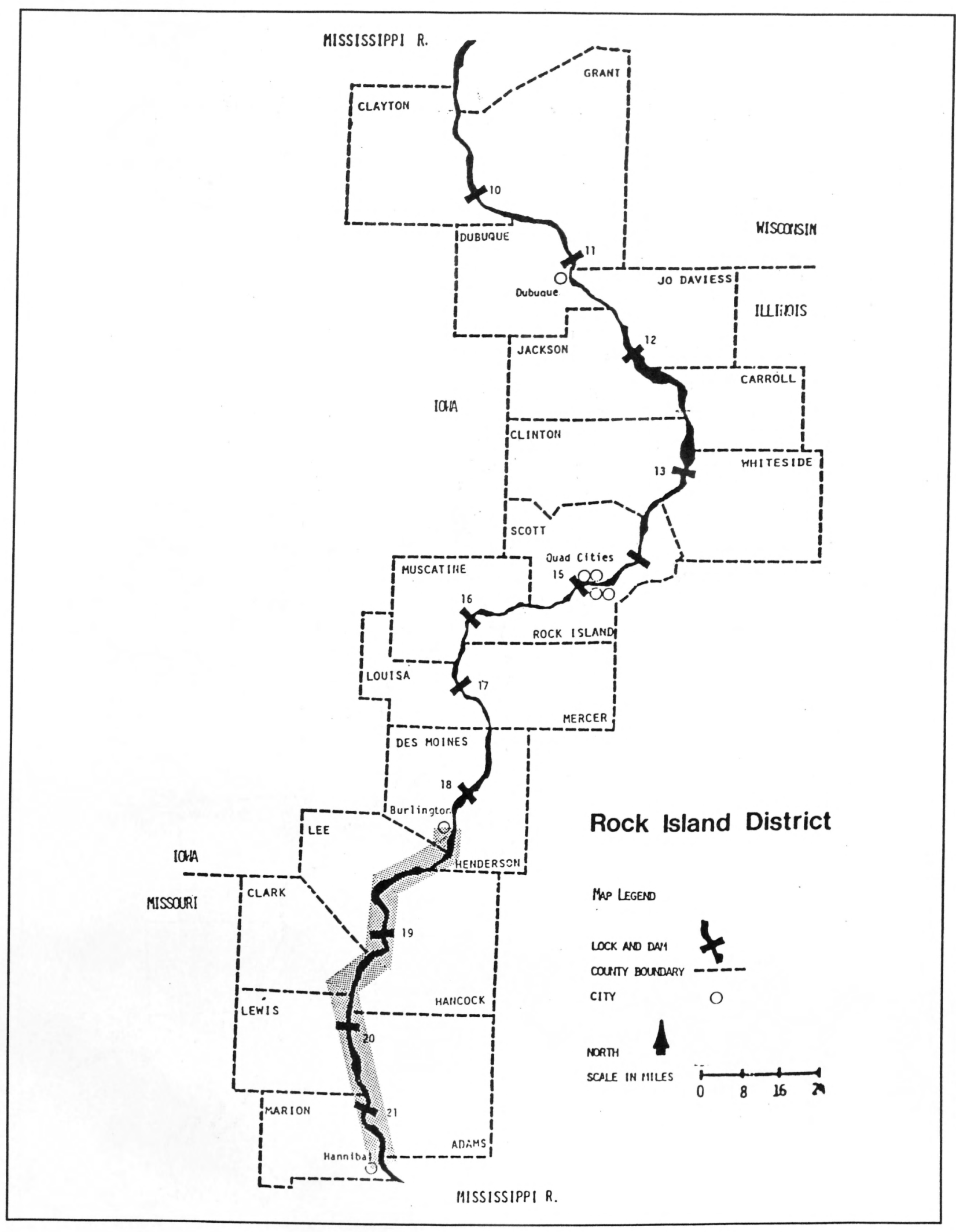

Figure A2. Rock Island District 


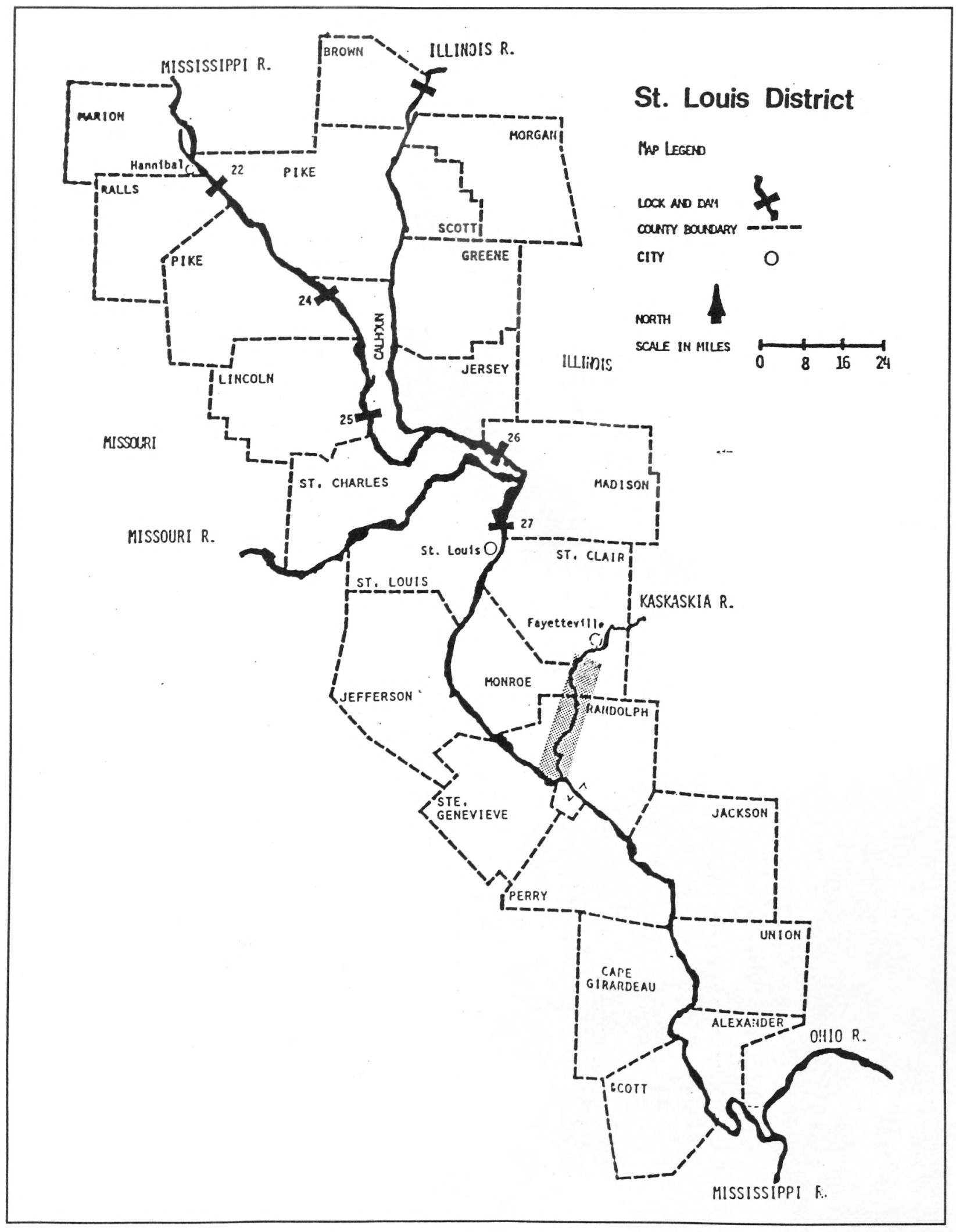

Figure A3. St. Louis District 


\section{Illinois River and Waterway}

Map Lecao
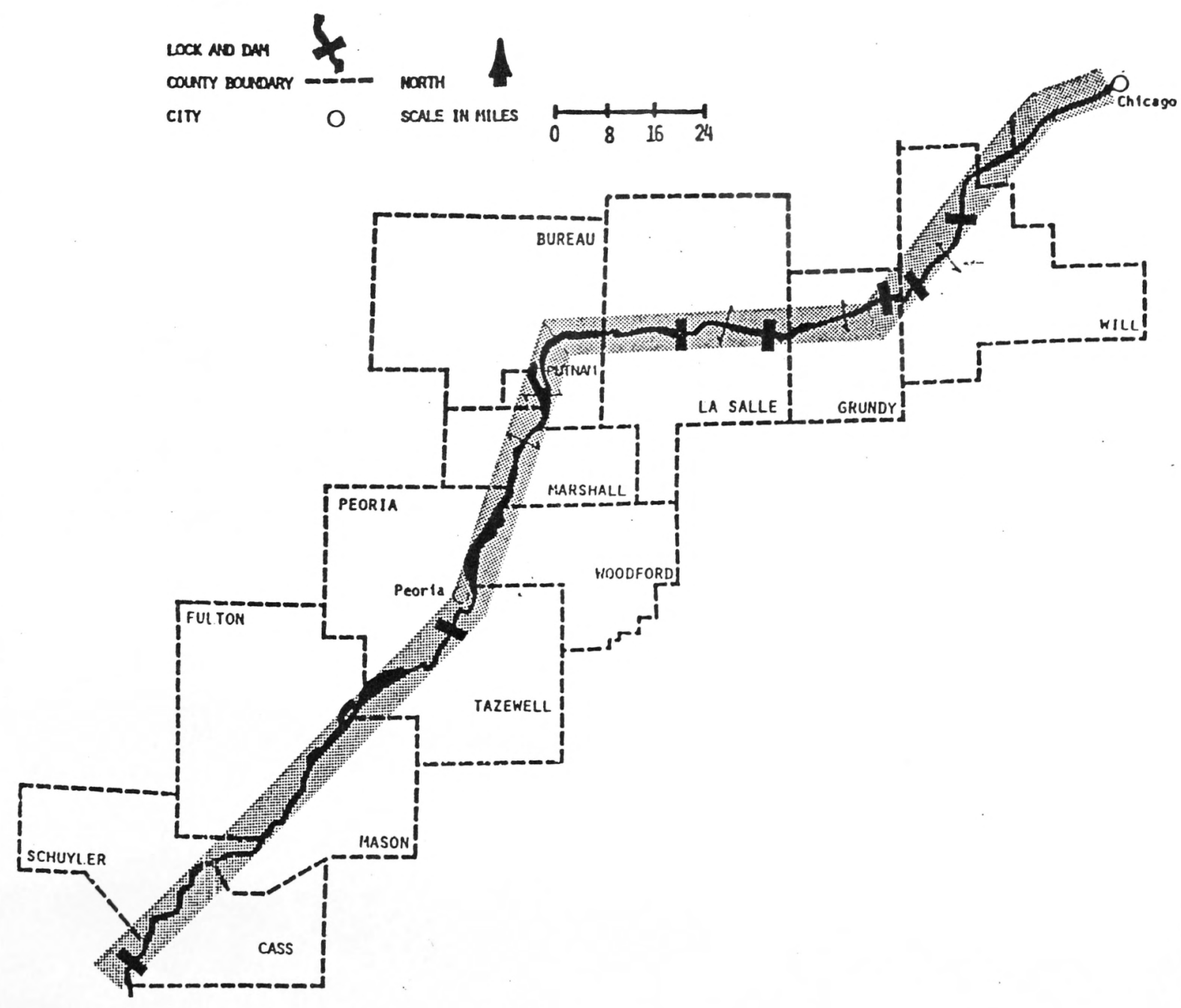

Figure A4. Illinois River and Waterway 

Public reporting burden for this collection of information is estimated to average 1 hour per response, including the time for reviewing instructions, searching existing data sources, gathering and maintaining the data needed, and completing and reviewing the collection of information. Send comments regarding this burden estimate or any other aspect of this
collection of information, including suggestions for reducing this burden, to washington Headquarters services. Directorate for Information Operations and Reports. 1215 Jefferson Davis Highway. Suite 1204, Arlington, VA 22202-4302, and to the Office of Management and Budget, Paperwork Reduction Project (0704-0 188), Washington, OC 20503.

\begin{tabular}{|c|c|c} 
1. AGENCY USE ONLY (Leave blank) & $\begin{array}{c}\text { 2. REPORT DATE } \\
\text { April } 1995\end{array}$ & $\begin{array}{c}\text { 3. REPORT TYPE AND DATES COVERED } \\
\text { Final report }\end{array}$ \\
\hline
\end{tabular}

4. TITLE AND SUBTITLE

5. FUNDING NUMBERS

Economic Impact of Recreation on the Upper Mississippi River System

6. AUTHOR(S)

Bruce D. Carlson, Dennis B. Propst, Daniel J. Stynes, R. Scott Jackson

\section{PERFORMING ORGANIZATION NAME(S) AND ADDRESS(ES)}

U. S. Army Engineer District, St. Paul, St. Paul, MN 55101-1638;

Michigan State University, East Lansing, MN 48824-1222;

U.S. Army Engineer Waterways Experiment Station

3909 Halls Ferry Road, Vicksburg, MS 39180-6199

9. SPONSORING/MONITORING AGENCY NAME(S) AND ADDRESS(ES)

U.S. Army Corps of Engineers

Washington, DC 20314-1000
8. PERFORMING ORGANIZATION REPORT NUMBER

Technical Report EL-95-16

10. SPONSORING/MONITORING AGENCY REPORT NUMBER

11. SUPPLEMENTARY NOTES

Available from National Technical Information Service, 5285 Port Royal Road, Springfield, VA 22161.

12a. DISTRIBUTION / AVAILABILITY STATEMENT

12b. DISTRIBUTION CODE

Approved for public release; distribution is unlimited.

13. ABSTRACT (Maximum 200 words)

This report presents the findings of a study of the economic impact of recreational use of the Upper Mississippi River System (UMRS). The study was authorized by Congress in 1986 under Public Law 99-88 to measure the economic importance of the UMRS as a recreational resource.

The study estimated that over 12 million daily visits were made by visitors to the UMRS during the study year. These visits resulted in direct and secondary expenditures of over $\$ 1.2$ billion that maintained over 18,000 jobs nationwide.

The study was conducted as a part of the UMRS Environmental Management Program (EMP). The EMP is a long-term program designed to protect and balance the resources of the Upper Mississippi and guide future river management.

14. SUBJECT TERMS

Economic impact Mississippi River Recreation

62

16. PRICE CODE

17. SECURITY CLASSIFICATION OF REPORT

18. SECURITY CLASSIFICATION OF THIS PAGE

UNCLASSIFIED

UNCLASSIFIED 
Destroy this report when no longer needed. Do not return it to the originator. 